\title{
Application of the Modified Mohr-Coulomb Yield Criterion in Seismic Numerical Simulation of Tunnels
}

\author{
Chuan-Yi Sui $\mathbb{D}^{1,2}$ Yu-Sheng Shen $\mathbb{D}^{1,},{ }^{1,3}$ Yu-Min Wen ${ }^{(D)},{ }^{2,3}$ and Bo Gao ${ }^{1,2}$ \\ ${ }^{1}$ Key Laboratory of Transportation Tunnel Engineering of Ministry of Education, Southwest Jiaotong University, \\ Chengdu 610031, China \\ ${ }^{2}$ School of Civil Engineering, Southwest Jiaotong University, Chengdu 610031, China \\ ${ }^{3}$ National Engineering Laboratory for Technology of Geological Disaster Prevention in Land Transportation, \\ Southwest Jiaotong University, Chengdu 610031, China
}

Correspondence should be addressed to Yu-Min Wen; wym@swjtu.edu.cn

Received 2 April 2021; Accepted 2 November 2021; Published 25 November 2021

Academic Editor: Marco Lepidi

Copyright ( 2021 Chuan-yi Sui et al. This is an open access article distributed under the Creative Commons Attribution License, which permits unrestricted use, distribution, and reproduction in any medium, provided the original work is properly cited.

To solve the classical problem that the Mohr-Coulomb yield criterion overestimates the tensile properties of geotechnical materials, a modified Mohr-Coulomb yield criterion that includes both maximum tensile stress theory and smooth processing was established herein. The modified Mohr-Coulomb constitutive model is developed using the user-defined material subroutine (UMAT) available in finite element software ABAQUS, and the modified Mohr-Coulomb yield criterion is applied to construct a numerical simulation of a shaking table model test. Compared with the measured data from the shaking table test, the accuracies of the classical Mohr-Coulomb yield criterion and the modified Mohr-Coulomb yield criterion are assessed. Compared to the shaking table test, the classical Mohr-Coulomb model has a relatively large average error $(-6.98 \%$ in peak acceleration values, $-8.47 \%$ in displacement values, $-23.93 \%$ in axial forces), while the modified Mohr-Coulomb model has a smaller average error $(+2.71 \%$ in peak accelerations value, $+3.19 \%$ in displacements value, $+7.56 \%$ in axial forces). The results of numerical simulation using the modified Mohr-Coulomb yield criterion are closer to the measured data.

\section{Introduction}

Since the Wenchuan earthquake in $2008(\mathrm{Ms}=8.0)$, China has suffered from numerous serious earthquakes, like the Kaohsiung earthquake $(\mathrm{Ms}=6.7,2016)$ and the Yushu earthquake (Ms $=7.1,2010)$ [1]. Most earthquakes pose potential threats to underground structures in mountainous areas. Taking the Longmen Mountain Fault Zone in the north-western margin of the Sichuan Basin as an example, an earthquake in this fault zone would impact a large number of traffic tunnels and underground structures. The subway stations and other underground structures were critically damaged $[2,3]$ in the Kobe earthquake in Japan, which were considered aseismic structures [4-7] in highintensity earthquake area. The Lushan earthquake $(\mathrm{Ms}=7.0$, 2013), the Jiuzhaigou earthquake ( $M s=7.0,2017)$, and the
Changning earthquake $(M s=6.0,2019)$ show that the tunnels within the Sichuan Basin are threatened by highintensity earthquakes. Therefore, studies of the seismic performance of underground structures should receive more attention.

There are three main types of approaches for the analysis of seismic performance of underground structures: field investigations, model tests, and numerical simulations [8-13]. Numerical simulation methods have been widely used to analyse the dynamic response of tunnel structure in some bad conditions, but the computational ability of computers and the mechanical models needs to be studied further in the existing software. Most numerical analysis results should be verified using field tests or model tests, and improvements in the accuracy for numerical analysis would be beneficial. 
The classical Mohr-Coulomb yield criterion is the most widely used constitutive model in geotechnical mechanics. It focuses on the response of brittle materials to shear stress and normal stress. However, classical Mohr-Coulomb theory overestimates the tensile properties of geotechnical materials. Jia and Chen's article shows that there are up to $18.7 \%$ differences in yield stress [14]. The dynamic response of the surrounding rocks in underground structures exhibits a clear tension-compression cycle during strong earthquake motion. When calculating the dynamic response of an underground structure, the classical Mohr-Coulomb yield criterion should be corrected.

Zienkiewicz and Pande suggested using a hyperbola to approximate the two Mohr-Coulomb straight lines in the meridional plane. Deng et al. proposed the equal-area-cone principle, which uses a series of modified Drucker-Prager yield criteria to replace the Mohr-Coulomb yield criterion. But, the replaceable Drucker-Prager criteria are related to the stress states of rocks, which means the criteria of every element used may be changed during a dynamic simulation and need more computing resources [15-19]. Jia et al. combined the classical Mohr-Coulomb theory with the maximum tensile stress theory, which uses a parameter $m$ to reduce the yield stress but leaves no definition of the parameter $m$ [20]. Based on these previous studies, a constitutive model with the tensile strength replacing the parameter $m$ in Jia's model was developed. The modified model was applied to the dynamic numerical simulation of underground structures, and its advantages were compared with those of the classical Mohr-Coulomb model.

\section{Modified Mohr-Coulomb Yield Criterion}

For the constitutive model of geotechnical materials, the yield function is expressed in the form of stress invariants for convenience, as shown in the following:

$$
\begin{aligned}
\sigma_{m} & =\frac{\left(\sigma_{1}+\sigma_{2}+\sigma_{3}\right)}{3} \\
\bar{\sigma} & =\sqrt{\frac{1}{2}\left(s_{x}^{2}+s_{y}^{2}+s_{z}^{2}\right)+\tau_{x y}^{2}+\tau_{x z}^{2}+\tau_{y z}^{2}}=\sqrt{J_{2}}, \\
J_{3} & =s_{x} s_{y} s_{z}+2 \tau_{x y} \tau_{x z} \tau_{y z}-s_{x} \tau_{y z}^{2}-s_{y} \tau_{x z}^{2}-s_{z} \tau_{x y}^{2},
\end{aligned}
$$

where $s_{x}=\sigma_{x}-\sigma_{m}, s_{y}=\sigma_{y}-\sigma_{m}, s_{z}=\sigma_{z}-\sigma_{m}$, and $\sigma_{m}$ is the mean stress, $\bar{\sigma}$ is the equivalent stress, and $\sigma \mathrm{m} J_{2}$ and $J_{3}$ are the second and the third stress invariants, respectively.

The Lode angel equation is as follows:

$$
\theta=\frac{1}{3} \sin ^{-1}\left(-\frac{3 \sqrt{3}}{2} \frac{J_{3}}{\bar{\sigma}^{2}}\right), \quad-30^{\circ} \leq \theta \leq 30^{\circ} .
$$

The classical Mohr-Coulomb model overestimates the tensile strength of materials. Jia et al. developed a modified Mohr-Coulomb yield criterion [20]; the yield function is given in (3). $K(\theta)$ represents the yield curves with different Lode angles in the $\pi$ plane. $K(\theta)$ is calculated using (4):

$$
\begin{aligned}
F= & \sigma_{m} \sin \phi+\sqrt{\bar{\sigma}^{2} K^{2}(\theta)+(m c \cos \phi)^{2}} \\
& -c \cos \phi=0, \\
K(\theta)= & \cos \theta-\frac{1}{\sqrt{3}} \sin \phi \sin \theta .
\end{aligned}
$$

When $m=0,(3)$ is identical to the yield function of Mohr-Coulomb model (5). However, Jia and Chen did not provide a physical definition or recommend a value for the parameter $m$ :

$$
\sigma_{m} \sin \phi+\bar{\sigma} K(\theta)-c \cos \phi=0 .
$$

The yield function of the maximum tensile stress theory is given in (6), where $T_{c}$ is the tensile strength:

$$
\frac{2}{\sqrt{3}} \bar{\sigma} \sin \left(\theta+120^{\circ}\right)+\sigma_{m}-T_{c} \geq 0 .
$$

Zienkiewicz and Pande suggested replacing the classical Mohr-Coulomb yield surface function with a hyperbola [19]:

$$
\frac{\left(\sigma_{m}-d\right)^{2}}{a^{2}}-\frac{\bar{\sigma}^{2}}{b^{2}}=1 .
$$

To fit Zienkiewicz and Pande's hyperbola (7) using the maximum tensile stress yield function (6), the parameters in (7) can be set as $a=c \cot \phi-T_{c}, b=\left(c \cot \phi-T_{c}\right) \sin \phi /$ $K(\theta)$, and $d=c \cot \phi . K(\theta)$ is defined in (4). (7) can be simplified to

$$
\begin{aligned}
F= & \sigma_{m} \sin \phi+\sqrt{\bar{\sigma}^{2} K^{2}(\theta)+\left(T_{c} \sin \phi-c \cos \phi\right)^{2}} \\
& -c \cos \phi=0 .
\end{aligned}
$$

In the following, the yield function of the modified Mohr-Coulomb is set as (8).

The classical Mohr-Coulomb yield surface is not smooth, and it has a singular vertex point. The corners and singular vertex point make the numerical calculations difficult. Shi and Yang suggest using a curve fit to approximate it [21]. Jia and Chen used a piecewise function to smooth the yield surface [20]. Since (8) is a special case of (3), Jia's $K(\theta)$ is introduced in (8). The result is obtained in

$$
\begin{aligned}
F= & \sigma_{m} \sin \phi+\sqrt{\bar{\sigma}^{2} K^{2}(\theta)+\left(T_{c} \sin \phi-c \cos \phi\right)^{2}} \\
& -c \cos \phi=0 .
\end{aligned}
$$

$K(\theta)$ is calculated using (10) and (12), as follows:

$$
\begin{aligned}
K(\theta)= & \cos \theta-\frac{1}{\sqrt{3}} \sin \phi \sin \theta, \quad \text { when }|\theta| \leq \theta_{T}, \\
K(\theta)= & \frac{1}{3} \cos \theta_{T}\left[3+\tan \theta_{T} \tan 3 \theta_{T}\right. \\
& \left.+\frac{1}{\sqrt{3}}\left(\tan 3 \theta_{T}-3 \tan \theta_{T}\right) \sin \phi\right]
\end{aligned}
$$


$-\frac{1}{3 \cos \theta_{T}}\left(\sin \theta_{T}+\frac{1}{\sqrt{3}} \sin \phi \cos \theta_{T}\right) \sin 3 \theta, \quad$ when $|\theta|>\theta_{T}$.

Based on Jia's research, $\theta_{T}=27^{\circ}$ is recommended. Limestone was used as an example. The cohesion is $60 \mathrm{kPa}$, the friction angle is $25^{\circ}$, and the tensile strength is $50 \mathrm{kPa}$. Figure 1 shows the curves of the constitutive model used in this paper and Jia's model in the stress space. The $x$-axis is the mean stress $\left(\sigma_{m}\right)$, and the $y$-axis is the equivalent stress $(\bar{\sigma})$.

As shown in Figure 1, the model proposed by Jia is sensitive to the value of parameter $m$ and no recommended value of $m$ is given in Jia's paper [20]. The uniaxial tensile strength is substituted for the parameter $m$. The constitutive model in this paper is similar to the classical Mohr-Coulomb constitutive model in the compression stage, and the control criterion of the tensile stress is approximated in the tensile section. The results are consistent with the experimental results under uniaxial tension.

The plastic potential function is consistent with the yield function:

$$
G=\sigma_{m} \sin \phi+\sqrt{\bar{\sigma}^{2} K^{2}(\theta)+\left(T_{c} \sin \phi-c \cos \phi\right)^{2}} .
$$

The parameters in (13) are identical as those in (9).

\section{Constitutive Model Used in ABAQUS Software}

ABAQUS $^{\text {TM }}$ can employ FORTRAN ${ }^{\text {TM }}$ programs to develop user-defined materials (UMATs). The calculation process of the general user subroutine [20] is shown in Figure 2.

3.1. Calculation of Plastic Parameters. When the stress exceeds the yield surface, it needs to adjust the stress and return to the updated yield surface (Figure 3). The method used is called the constitutive integration algorithm [20].

As shown in Figure 3, the stress state at point $\mathrm{A}\left(\sigma_{A}\right)$ is in the yield plane, while that at point $\mathrm{B}\left(\sigma_{B}\right)$ is outside of the yield plane:

$$
\begin{aligned}
\sigma_{B} & =\sigma_{A}+D_{e} \Delta \varepsilon \\
& =\sigma_{A}+\Delta \sigma_{e} .
\end{aligned}
$$

In (14), $D_{e}$ is the elastic matrix, $\Delta \sigma_{e}$ is the elastic stress increment, and $\sigma_{B}$ is the probing stress. To bring the probing stress $\sigma_{B}$ into the yield plane, the change in the stress $\Delta \sigma$ is calculated in (15), where $b=\partial G / \partial \sigma$ :

$$
\begin{aligned}
\Delta \sigma & =D_{e} \Delta \varepsilon-\Delta \lambda D_{e} b \\
& =\Delta \sigma_{e}-\Delta \lambda D_{e} b .
\end{aligned}
$$

The stress at point $\mathrm{C}$ is calculated in

$$
\sigma_{C}=\sigma_{B}-\Delta \lambda D_{e} b .
$$

The function of the backward Euler algorithm is to gradually iterate point $\mathrm{C}$ onto the yield surface. The yield function $\mathrm{F}$ is expanded using a first-order Taylor expansion at point $\mathrm{B}$ :

$$
\begin{aligned}
F & =F_{B}+\left(\frac{\partial F}{\partial \sigma}\right)^{T} \Delta \sigma+\frac{\partial F}{\partial \overline{\varepsilon_{p l}}} \Delta \overline{\overline{\varepsilon_{p l}}} \\
& =F_{B}-\Delta \lambda a_{B}^{T} D_{e} b_{B}-\Delta \lambda A_{B}^{\prime}=0, \\
\Delta \lambda & =\frac{F_{B}}{a_{B}^{T} D_{e} b_{B}+A_{B}^{\prime}} .
\end{aligned}
$$

The backward Euler algorithm is used to pull the stress back to the yield surface, as follows:

$$
\sigma_{C}=\sigma_{B}-\Delta \lambda D_{e} b_{C} .
$$

The initial estimate of $\sigma_{C}$ is based on the stress at point B:

$$
\sigma_{C}=\sigma_{B}-\Delta \lambda D_{e} b_{B} .
$$

The vector $r$ is defined as the difference between the current stress and the backward Euler stress:

$$
\begin{aligned}
r & =\sigma-\left(\sigma_{B}-\Delta \lambda D_{e} b_{C}\right) \\
& =\sigma-\sigma_{B}+\Delta \lambda D_{e} b_{C} .
\end{aligned}
$$

When $r=0$, the stress is back on the yield plane. The Taylor expansion of $r$ with fixed $\sigma_{B}$ is

$$
r_{n}=r_{0}+\dot{\sigma}+\dot{\lambda} D_{e} b+\Delta \lambda D_{e} \frac{\partial b}{\partial \sigma} \dot{\sigma} .
$$

When $r_{n}=0$,

$$
\begin{aligned}
\dot{\sigma} & =-\left(I+\Delta \lambda D_{e} \frac{\partial b}{\partial \sigma}\right)^{-1}\left(r_{0}+\dot{\lambda} D_{e} b\right) \\
& =-Q^{-1} r_{0}-\dot{\lambda} Q^{-1} D_{e} b .
\end{aligned}
$$

$I$ is the identity matrix.

The Taylor expansion of the yield function $\mathrm{F}$ at point $\mathrm{C}$ is as follows:

$$
F_{\mathrm{Cn}}=F_{C 0}+\left(\frac{\partial F}{\partial \sigma}\right)^{T} \dot{\sigma}+\frac{\partial F}{\partial \overline{\varepsilon_{\mathrm{pl}}}} \dot{\overline{\varepsilon_{\mathrm{pl}}}}=F_{C 0}+a_{C}^{T} \dot{\sigma}+A_{C}^{\prime} \dot{\lambda}=0 .
$$

Substituting (22) into (23) gives

$$
\dot{\lambda}=\frac{F_{C}-a_{C}^{T} Q^{-1} r_{0}}{a_{C}^{T} Q^{-1} D_{e} b+A_{C}^{\prime}} .
$$

The equivalent plastic strain rate $1 / \varepsilon_{p l}$ is as follows:

$$
\frac{\dot{\varepsilon_{p l}}}{=} \dot{\lambda} B(\sigma) .
$$

For the von Mises yield criteria, $B(\sigma)=1$, whereas for the yield criterion of rock and soil, $B(\sigma) \neq 1$.

3.2. Solution of the Stiffness Matrix of the Same Tangent $\mathbf{D}_{\mathbf{c t}}$. According to (19), if the subscript of the stress state $C$ of the current configuration in the following formula is ignored 


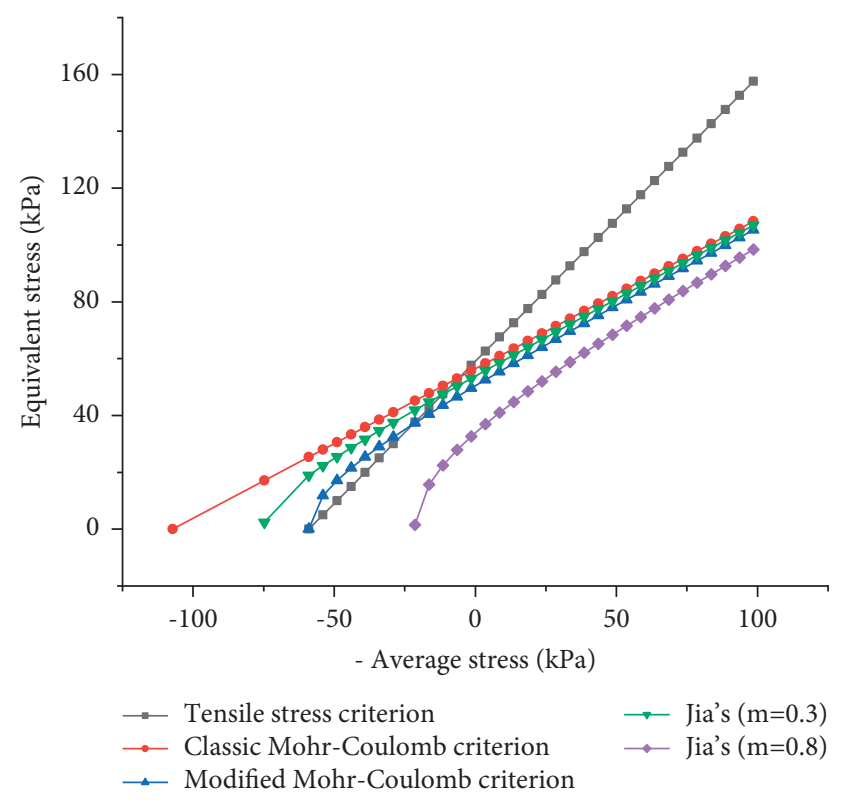

FIGURE 1: Yield criterion function used in this article.

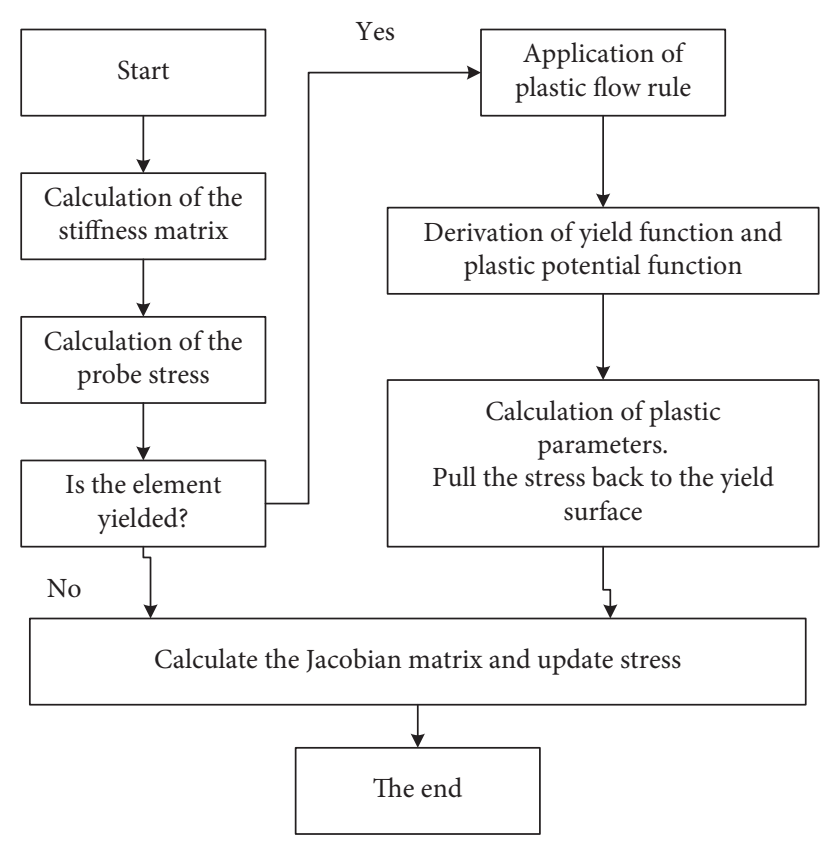

FIgURE 2: Flow chart of the UMAT used in ABAQUS software.

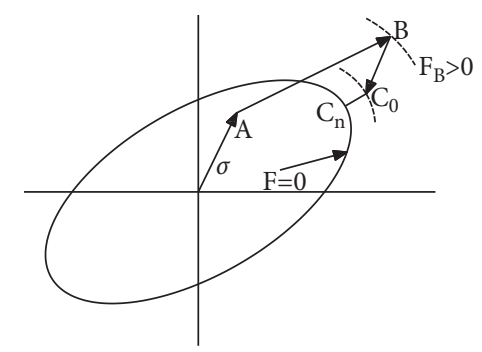

FIgURE 3: Diagram of the backward Euler integration algorithm. and the subscript B represents the elastic probing stress, (19) can be expressed as

$$
\sigma=\sigma_{B}-\Delta \lambda D_{e} b .
$$

The differential form of (26) is

$$
\dot{\sigma}=D_{e} \dot{\varepsilon}-\dot{\lambda} D_{e} b-\Delta D_{e} \frac{\partial b}{\partial \sigma} \dot{\sigma} .
$$

The simplified form of (27) is as follows:

$$
\begin{aligned}
\dot{\sigma} & =\left(I+\Delta \lambda D_{e} \frac{\partial b}{\partial \sigma}\right)^{-1} D_{e}(\dot{\varepsilon}-\dot{\lambda} b) \\
& =Q^{-1} D_{e}(\dot{\varepsilon}-\dot{\lambda} b)=R(\dot{\varepsilon}-\dot{\lambda} b),
\end{aligned}
$$

where $R=Q^{-1} D_{e}$.

To bring the stress $\sigma$ back to the yield plane, $\dot{F}=0$ is needed. According to the yield function F, the consistency conditions are as follows:

$$
\dot{F}=a^{T} \dot{\sigma}-A^{\prime} \dot{\lambda}=0
$$

Substituting (28) into (29) gives

$$
\dot{\lambda}=\frac{\mathbf{a}^{T} R \dot{\varepsilon}}{\mathbf{a}^{T} R b+A^{\prime}} .
$$

Substituting (30) into (27) gives

$$
\begin{aligned}
\dot{\sigma} & =\left(R-\frac{R b \mathbf{a}^{T} R^{T}}{\mathbf{a}^{T} R b+A^{\prime}}\right) \dot{\varepsilon} \\
& =D_{c t} \dot{\varepsilon} .
\end{aligned}
$$

The stiffness matrix of the same tangent is $D_{\mathrm{ct}}$.

3.3. Newton-Raphson Iterative Algorithm for Plastic Parameters under the $n^{\text {th }}$ Loading Step. In the fully implicit backward Euler method, the plastic strain and the equivalent plastic strain increment are calculated at the end of the $n$th incremental step. The integral algorithm can be expressed as follows:

$$
\left\{\begin{array}{l}
\varepsilon^{(n+1)}=\varepsilon^{(n)}+\Delta \varepsilon, \\
\varepsilon_{p}^{(n+1)}=\varepsilon_{p}^{(n)}+\Delta \lambda^{(n+1)} b^{(n+1)}, \\
\bar{\varepsilon}_{p l}^{(n+1)}=\bar{\varepsilon}_{p l}^{(n)}+\Delta \lambda^{(n+1)} B^{(n+1)}, \\
\sigma^{(n+1)}=D_{e}:\left(\varepsilon^{(n+1)}-\varepsilon_{p}^{(n+1)}\right), \\
F^{(n+1)}=F^{(n+1)}\left(\sigma^{(n+1)}, \bar{\varepsilon}_{p l}^{(n+1)}\right) .
\end{array}\right.
$$

(32) includes nonlinear equations about $\left(\varepsilon^{(n+1)}, \varepsilon_{p}^{(n+1)}\right.$, $\left.\bar{\varepsilon}_{\mathrm{pl}}^{(n+1)}\right)$ and $\left(\varepsilon^{(n)}, \varepsilon_{p}^{(n)}, \bar{\varepsilon}_{\mathrm{pl}}^{(n)}\right)$, and the strain increment $\Delta \varepsilon=\Delta t \dot{\varepsilon}$ is given at $t_{n}$. These nonlinear equations are solved using the Newton-Raphson iterative method, and the stresses are updated as follows.

Step 1. The initial values of the plastic strain and the equivalent plastic strain are the convergence values at the 
end of the last loading step. The incremental value of the plastic parameter is set to 0 to calculate the elastic stress as follows:

$$
\begin{aligned}
k & =0: \varepsilon_{p(0)}^{(n)}=\varepsilon_{p}^{(n-1)}, \\
\bar{\varepsilon}_{p l(0)}^{(n)} & =\bar{\varepsilon}_{p l}^{(n-1)}, \\
\Delta \lambda_{0}^{(n)} & =0, \\
\sigma_{(0)}^{(n)} & =D_{e}:\left(\varepsilon^{(n)}-\varepsilon_{p(0)}^{(n)}\right) .
\end{aligned}
$$

Step 2. Check the yield condition and convergence of the $\mathrm{k}$-th iteration.

$$
F_{(k)}^{(n)}=F\left(\sigma_{(k)}^{(n)}, \bar{\varepsilon}_{\mathrm{pl}(k)}^{(n)}\right) .
$$

If $F_{(k)}^{(n)}<$ tolerance, the calculation is convergent. Otherwise, proceed to Step 3.

Step 3. The increment of the plastic parameter is calculated, and the increments of the stress and the equivalent plastic strain are obtained.

$$
\begin{aligned}
\delta \lambda_{(k)} & =\frac{F_{(k)}-a_{(k)}^{T} Q^{-1} r_{0}}{a_{(k)}^{T} Q^{-1} D_{e} b+A_{(k)}^{\prime}}, \\
\delta \sigma_{(k)} & =-\left(I+\Delta \lambda D_{e} \frac{\partial b}{\partial \sigma}\right)^{-1}\left(r_{0}+\dot{\lambda} D_{e} b\right), \\
\delta \bar{\varepsilon}_{\mathrm{pl}(k)} & =\delta \lambda_{(k)} B .
\end{aligned}
$$

Step 4. The plastic strain, stress, and plastic multiplier are updated.

$$
\left\{\begin{array}{l}
\Delta \lambda_{(k+1)}=\Delta \lambda_{(k)}+\delta \lambda_{(k)}, \\
\bar{\varepsilon}_{p l(k+1)}^{(n)}=\bar{\varepsilon}_{p l(k)}^{(n)}+\delta \bar{\varepsilon}_{p l(k)}, \\
\varepsilon_{p l(k+1)}^{(n)}=\varepsilon_{p l(k)}^{(n)}+D_{e}^{-1}: \delta \sigma_{k}, \\
\sigma_{(k+1)}^{(n)}=\sigma_{(k)}^{(n)}+D_{e}:\left(\varepsilon^{(n)}-\varepsilon_{p l(k+1)}^{(n)}\right) .
\end{array}\right.
$$

Set $k=k+1$, and return to Step 3 .

When using the implicit backward Euler algorithm, the first derivative of the yield function, the first derivative of the potential function, and the second derivative of the potential function are needed.

\subsection{Derivations of Yield Function and Potential Function}

3.4.1. The First Derivative of Yield Function. The vector $a$ is the derivative of the yield function with stress:

$$
\begin{aligned}
a & =\frac{\partial F}{\partial \sigma} \\
& =C_{1}^{\prime} \frac{\partial \sigma_{m}}{\partial \sigma}+C_{2}^{\prime} \frac{\partial \bar{\sigma}}{\partial \sigma}+C_{3}^{\prime} \frac{\partial J_{3}}{\partial \sigma} .
\end{aligned}
$$

where $C_{1}^{\prime}=\partial F / \partial \sigma_{m} ; C_{2}^{\prime}=\partial F / \partial \bar{\sigma}-\tan 3 \theta / \bar{\sigma} \partial F / \partial \theta ;$ an $d$ $C_{3}^{\prime}=-\sqrt{3} / 2 \cos 3 \theta \bar{\sigma}^{3} \partial F / \partial \theta$. The other parameters are calculated as follows:

$$
\frac{\partial J_{3}}{\partial \sigma}=\left\{\begin{array}{c}
s_{y} s_{z}-\tau_{y z}^{2} \\
s_{x} s_{z}-\tau_{x z}^{2} \\
s_{x} s_{y}-\tau_{x y}^{2} \\
2\left(\tau_{y z} \tau_{x z}-s_{z} \tau_{x y}\right) \\
2\left(\tau_{x y} \tau_{y z}-s_{y} \tau_{x z}\right) \\
2\left(\tau_{x z} \tau_{x y}-s_{x} \tau_{y z}\right)
\end{array}\right\}+\frac{\bar{\sigma}^{2}}{3}\left\{\begin{array}{l}
1 \\
1 \\
1 \\
0 \\
0 \\
0
\end{array}\right\},
$$

$$
\frac{\partial \sigma_{m}}{\partial \sigma}=\frac{1}{3}[1,1,1,0,0,0]^{T},
$$

$$
\begin{aligned}
\frac{\partial \bar{\sigma}}{\partial \sigma} & =\frac{1}{2 \bar{\sigma}}\left[s_{x}, s_{y}, s_{z}, 2 \tau_{x y}, 2 \tau_{x z}, 2 \tau_{y z}\right]^{T}, \\
C_{1}^{\prime} & =\sin \phi, \\
C_{2}^{\prime} & =\alpha^{\prime}\left(K-\tan 3 \theta \frac{\mathrm{d} K}{\mathrm{~d} \theta}\right), \\
C_{3}^{\prime} & =\alpha^{\prime}\left(-\frac{\sqrt{3}}{2 \cos 3 \theta \bar{\sigma}^{2}} \frac{\mathrm{d} K}{\mathrm{~d} \theta}\right), \\
\alpha^{\prime} & =\frac{\bar{\sigma} K}{\sqrt{\bar{\sigma}^{2} K^{2}+\left(T_{c} \sin \phi-c \cos \phi\right)^{2}}}, \\
\frac{\mathrm{d} K}{d \theta} & =\left\{\begin{array}{l}
-3 B \cos 3 \theta, \\
\sin \theta-\frac{1}{\sqrt{3}} \sin \phi \cos \theta, \quad|\theta| \leq \theta_{T} .
\end{array}\right.
\end{aligned}
$$

3.4.2. The First Derivative of Potential Function. The vector $b$ is the derivative of the potential function with stress:

$$
b=\frac{\partial G}{\partial \sigma}=C_{1} \frac{\partial \sigma_{m}}{\partial \sigma}+C_{2} \frac{\partial \bar{\sigma}}{\partial \sigma}+C_{3} \frac{\partial J_{3}}{\partial \sigma} .
$$

where $C_{1}=\partial G / \partial \sigma_{m} ; C_{2}=\partial G / \partial \bar{\sigma}-\tan 3 \theta / \bar{\sigma} \partial G / \partial \theta$; and $C_{3}=-\sqrt{3} / 2 \cos 3 \theta \bar{\sigma}^{3} \partial G / \partial \theta$. The other parameters are calculated as follows:

$$
\begin{aligned}
& C_{1}=\sin \phi, \\
& C_{2}=\alpha C_{2}^{m c}, \\
& C_{3}=\alpha C_{3}^{m c} .
\end{aligned}
$$

The calculation of $d K / d \theta$ is shown in (39). The calculation of $\alpha$ is shown in 


$$
\begin{aligned}
\alpha & =\frac{\bar{\sigma} K}{\sqrt{\bar{\sigma}^{2} K^{2}+\left(T_{c} \sin \phi-c \cos \phi\right)^{2}}}, \\
C_{2}^{m c} & =K-\tan 3 \theta \frac{\mathrm{d} K}{d \theta}, \\
C_{3}^{m c} & =-\frac{\sqrt{3}}{2 \cos 3 \theta \bar{\sigma}^{2}} \frac{\mathrm{d} K}{d \theta} .
\end{aligned}
$$

$$
\begin{gathered}
\frac{\partial b}{\partial \sigma}=\frac{\partial^{2} G}{\partial \sigma^{2}}=\frac{\partial C_{2}}{\partial \sigma} \frac{\partial \bar{\sigma}}{\partial \sigma}+C_{2} \frac{\partial^{2} \bar{\sigma}}{\partial \sigma^{2}}+\frac{\partial C_{3}}{\partial \sigma} \frac{\partial J_{3}}{\partial \sigma}+C_{2} \frac{\partial^{2} J_{3}}{\partial \sigma^{2}}, \\
\cdot\left\{\begin{array}{l}
\frac{\partial C_{2}}{\partial \sigma}=\alpha \frac{\partial C_{2}^{\mathrm{mc}}}{\partial \sigma}+C_{2}^{\mathrm{mc}} \frac{\partial \alpha}{\partial \sigma} \\
\frac{\partial C_{3}}{\partial \sigma}=\alpha \frac{\partial C_{3}^{\mathrm{mc}}}{\partial \sigma}+C_{3}^{\mathrm{mc}} \frac{\partial \alpha}{\partial \sigma}
\end{array}\right.
\end{gathered}
$$

where

\subsubsection{Quadratic Derivation of Plastic Potential Function.}

$$
\begin{aligned}
& \left\{\begin{array}{l}
\frac{\partial C_{2}^{m c}}{\partial \sigma}=\frac{\partial \theta}{\partial \sigma}\left(\frac{\partial K}{\partial \theta}+\frac{\partial^{2} K}{\partial \theta^{2}} \tan 3 \theta-3 \frac{\partial K}{\partial \theta} \sec ^{2} 3 \theta\right) \\
\frac{\partial C_{3}^{m c}}{\partial \sigma}=\frac{\sqrt{3}}{2 \cos 3 \theta \bar{\sigma}^{2}}\left[\frac{\partial \theta}{\partial \sigma}\left(\frac{\partial^{2} K}{\partial \theta^{2}}-3 \frac{\partial K}{\partial \theta} \tan 3 \theta\right)+\frac{2}{\bar{\sigma}} \frac{\partial K}{\partial \theta} \frac{\partial \bar{\sigma}}{\partial \sigma}\right] \\
\frac{\partial \alpha}{\partial \sigma}=\frac{1-\alpha^{2}}{\sqrt{\bar{\sigma}^{2} K^{2}+\left(T_{c} \sin \phi-c \cos \phi\right)^{2}}}\left(\frac{\partial \bar{\sigma}}{\partial \sigma} K+\bar{\sigma} \frac{\partial K}{\partial \theta} \frac{\partial \theta}{\partial \sigma}\right) \\
\frac{\partial \theta}{\partial \sigma}=-\frac{\sqrt{3}}{2 \bar{\sigma}^{3} \cos 3 \theta}\left(\frac{\partial J_{3}}{\partial \sigma}-\frac{3 J_{3}}{\bar{\sigma}} \frac{\partial \bar{\sigma}}{\partial \sigma}\right)
\end{array},\right.
\end{aligned}
$$

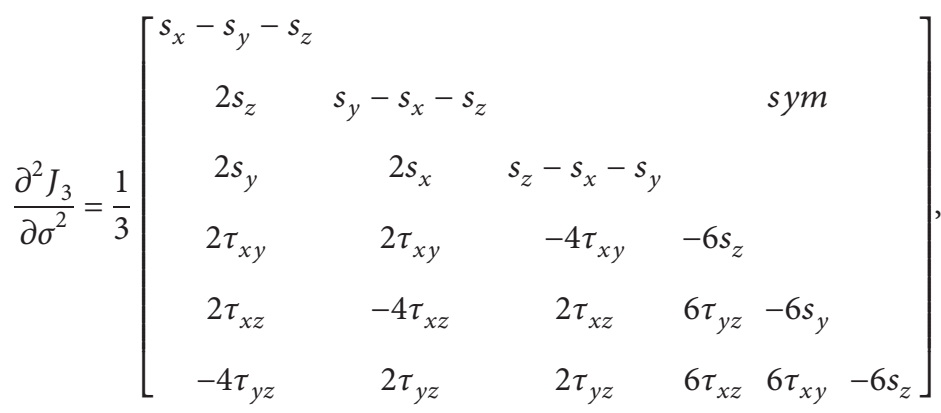

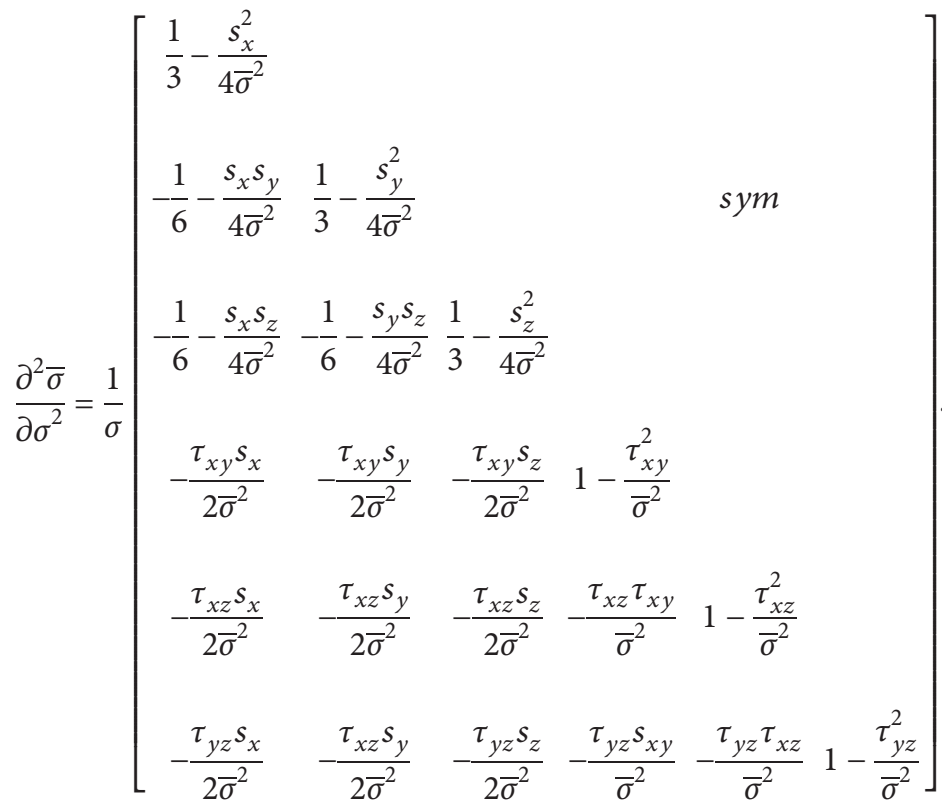




\section{Verification of the Modified Model}

Through comparison to the actual data from the shaking table test, the relative errors of both the improved Mohr-Coulomb model and the classical Mohr-Coulomb model were calculated. The calculation accuracy of the improved constitutive model was analysed.

4.1. Introduction to the Shaking Table Test. The primary objective of the shaking table test was to test how the vibration-absorptive material protects a tunnel in a fault zone [21]. The overall layout of the shaking table is shown in Figures 4 and 5. The detailed accelerometer monitoring plan is presented in Table 1. The rock surrounding the tunnel between the two fault zones is placed on a movable platform with $10 \mathrm{~cm}$-thick foam pieces on both the left and right sides. Both the left and right sides of the model contain a $25 \mathrm{~cm}$ thick foam board to absorb the reflected earthquake waves. The accelerometers used in the test were LC0113 M piezoelectric accelerometers [22] (Figures 6 and 7). Strain gauges used in the test were BX120-50AA resin-based strain gauges.

The prototype of the model is the Longxi tunnel which was highly damaged in the Wenchuan earthquake. The input wave of the shaking table is part of the east and west vector components of the Wolong seismic waves which is widely used in simulating tunnel dynamic response [21]. The original seismic wave lasts for $180 \mathrm{~s}$, and the peak acceleration value is $0.98 \mathrm{~g}$. The input wave occurs at $20 \mathrm{~s}$ to $110 \mathrm{~s}$. The time history curve of the input wave is shown in Figure 8. The frequency-domain analysis shown in Figure 9 suggests that the predominant frequency is about $2.3 \mathrm{~Hz}$ and the majority of the frequency domain is below $10 \mathrm{~Hz}$.

In view of the limitations of the shaking table and considering the similarity criterion, the length similarity ratio was taken as $1: 25$, the density similarity ratio as $1: 1.3$, and the stress similarity ratio as $1: 32.5$. A detailed list of similarity relations is presented in Table 2 .

The prototype model for the rock material is classified as Grade $\mathrm{V}$ according to the Chinese railway tunnel design specifications (TB10003-2005) [23]. The prototype for the surrounding rock is strongly weathered rock. The prototype lining material is C30 concrete. The prototype for the fault zone is gravel. The material similarity relationships are detailed in Tables 3-5.

4.2. Introduction to the Numerical Simulation. The numerical simulation was conducted using ABAQUS ${ }^{\mathrm{TM}}$ software. The overall model layout is shown in Figure 10. The model is based on the shaking table test, and the modeling is $1: 1$. A viscoelastic boundary was introduced to absorb the reflected earthquake waves. The physical parameters are shown in Table 6. The prototype surrounding rock is a strongly weathered rock mass, and the tensile strength of the model material is $3.0 \mathrm{kPa}$ [24]. The stiffness damping coefficient of the foam board and the damping material is 0.2 .

The input earthquake wave shown in Figure 11 is the first $26 \mathrm{~s}$ acceleration of the shaking table test. The maximum horizontal acceleration of the input wave is $0.97 \mathrm{~g}$, and the sampling is $200 \mathrm{~Hz}$.

The maximum frequency of the seismic wave is $100 \mathrm{~Hz}$; the seismic wave velocity in the surrounding rock is $1.35 \mathrm{~km} /$ $\mathrm{s}$; and the maximum length of the model units is $10 \mathrm{~cm}$, which is less than one-tenth of the maximum frequency corresponding to the seismic wave wavelength. The boundary filtering effect is negligible. Rayleigh damping was introduced in the dynamic analysis, and the damping matrix is $C=\eta M+\beta$ :

$$
\begin{aligned}
& \eta=\frac{2 \omega_{i} \omega_{j}}{\omega_{i}+\omega_{j}} \zeta, \\
& \beta=\frac{2}{\omega_{i}+\omega_{j}} \zeta,
\end{aligned}
$$

where $\zeta$ is the $i$ th- or $j$ th-order damping ratio of the natural vibration frequency. $\zeta_{i}=\zeta_{j}$ and $\omega_{i}$ and $\omega_{j}$ are the $i$ th- and $j$ th- order natural vibration frequencies, respectively. The damping ratio was obtained from the test and is $\zeta=0.15$. When running the modal analysis in ABAQUS ${ }^{\mathrm{TM}}$ software, the $1^{\text {st }}$ to $6^{\text {th }}$ orders of the natural vibration frequency are acquired (Table 7).

The Rayleigh damping parameters of the surrounding rock were calculated as follows: $\eta=1.951$ and $\beta=0.009$.

\subsection{Acceleration Analysis of the Modified Mohr-Coulomb} Model. The peak accelerations are introduced as the measurements [25-29]. By comparing the acceleration watch points of the two Mohr-Coulomb models with the results of the shaking table test, the peak acceleration similarity advantage of the modified Mohr-Coulomb yield criterion was assessed.

As shown in Figures 12-19, both the classical and modified Mohr-Coulomb yield criteria have acceleration time histories similar to those of the shaking table test, which indicates that both the classical and modified Mohr-Coulomb yield criteria can relatively truly represent the transmitted earthquake wave observed in the shaking table test.

Based on Figures 13, 15, 17, and 19, the modified Mohr-Coulomb yield criterion has more similar waveforms in the low frequency band $(<10 \mathrm{~Hz})$ than the classical Mohr-Coulomb yield criterion. The amplitudes of the modified Mohr-Coulomb criterion are closer to the test data than those of the classical ones. The frequencies of each peak in the modified model are closer than those of the classical model. In the middle frequency band $(10-15 \mathrm{~Hz})$, both the classical and modified Mohr-Coulomb yield criteria have lower accelerations than the shaking table test. However, further research is still required. In the high frequency band $(>15 \mathrm{~Hz})$, the two Mohr-Coulomb yield criteria and the shaking table test have little energy $(<0.005)$.

As reported in Table 8, the modified Mohr-Coulomb yield criterion has more similar peak accelerations than the classical Mohr-Coulomb yield criterion. Compared to the shaking table test, the acceleration of the modified 


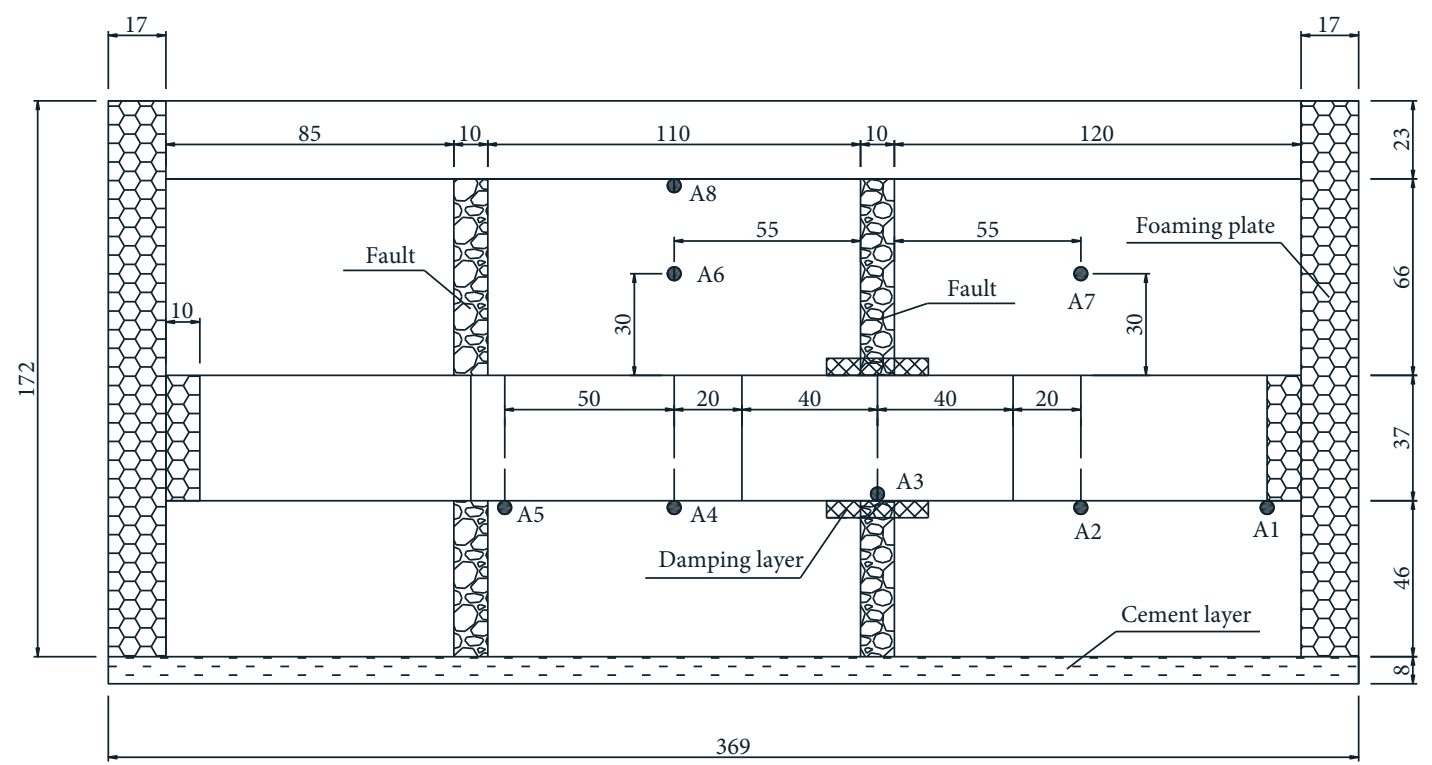

(a)

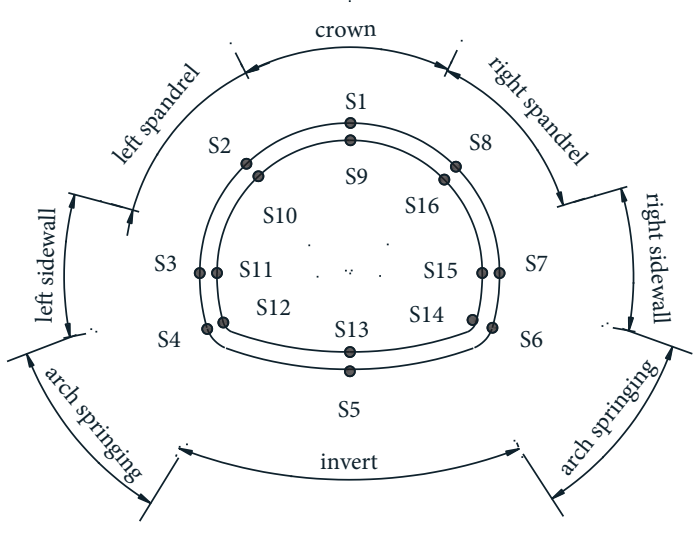

(b)

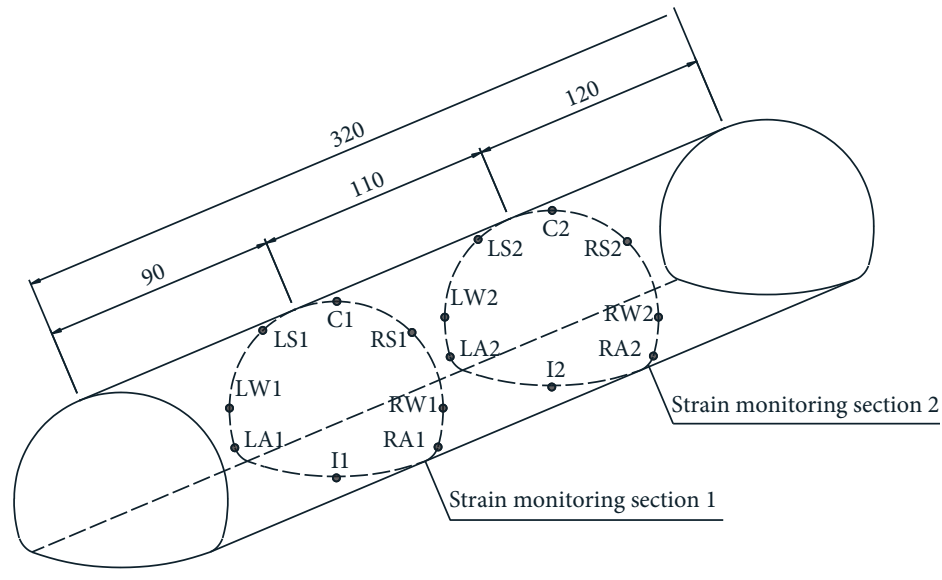

(c)

FIGURE 4: Layout of the shaking table test (all dimensions are in $\mathrm{cm}$ ). (a) Longitudinal plane of the test and layout of accelerometers. (b) Cross section of layout for strain gauges. (c) Layout of strain monitoring sections.

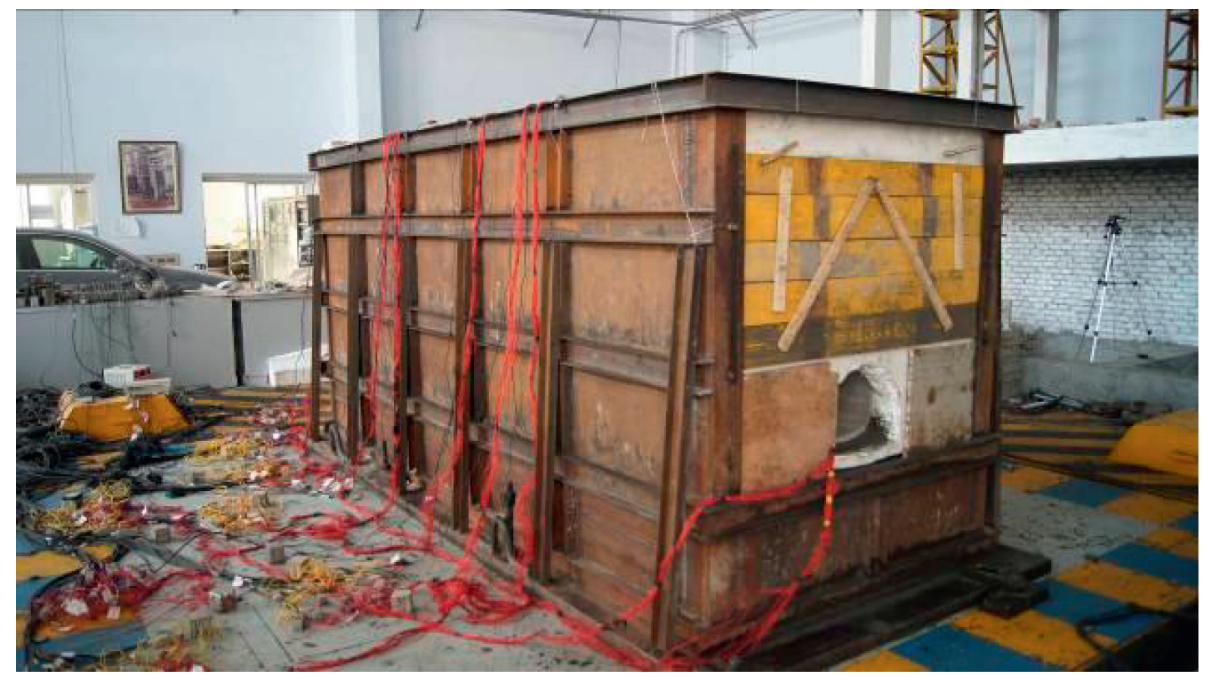

FIgUre 5: Photograph of the shaking table test. 
TABLE 1: Accelerometers and test objects.

\begin{tabular}{lc}
\hline Accelerometers & Test objects \\
\hline A1H & Boundary acceleration \\
A2H & $\begin{array}{r}\text { Rock acceleration near the damping layer } \\
\text { Tunnel acceleration at the fault with a damping } \\
\text { A3H }\end{array}$ \\
A4H & layer \\
A5H & Rock acceleration at the fault without a damping \\
A6H & layer \\
A7H & Rock acceleration between the faults \\
A8H & Rock acceleration near the damping layer \\
\end{tabular}

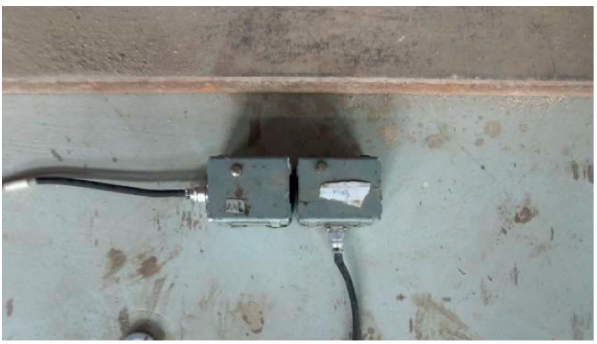

Figure 6: Accelerometers installed on the shaking table.

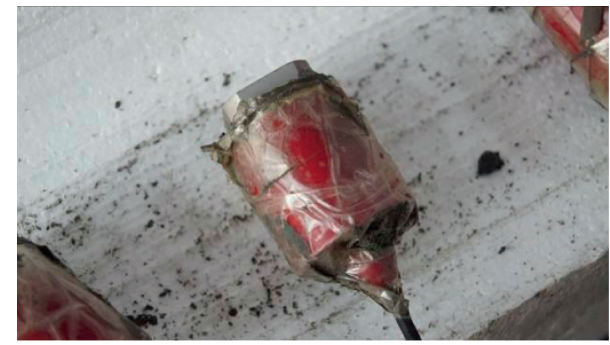

FIgURE 7: Accelerometers buried in the simulation material.

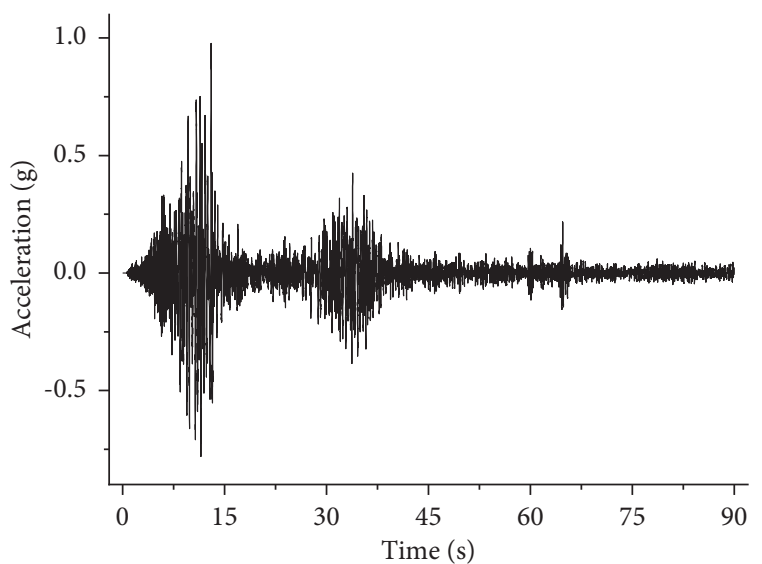

Figure 8: Time history curve of the input Wuolong wave for the shaking table test.

Mohr-Coulomb yield criterion at $\mathrm{A} 4 \mathrm{H}$ is $2.8 \%$ smaller, while that of the classical Mohr-Coulomb yield criterion is $8.8 \%$ smaller. At $\mathrm{A} 5 \mathrm{H}$, the acceleration of the modified

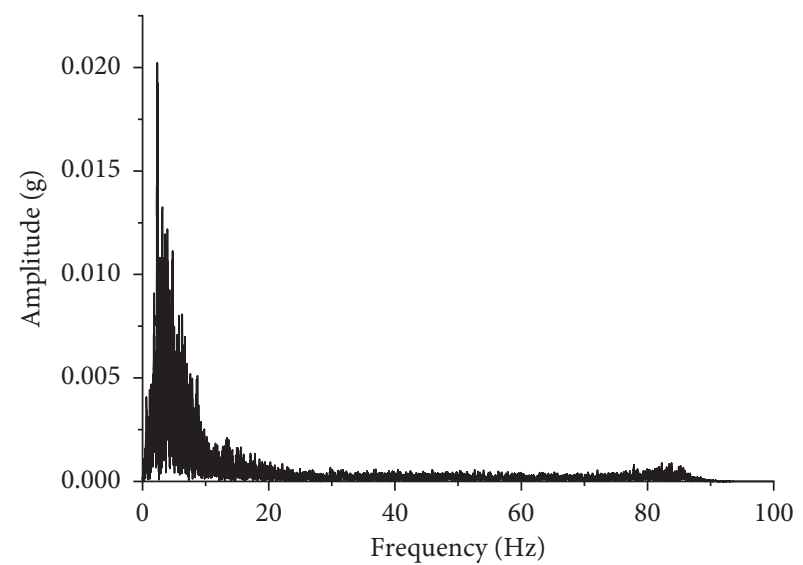

Figure 9: Frequency-domain analysis of acceleration of the Wuolong wave.

TABLE 2: Similarity ratios of the shaking table test.

\begin{tabular}{lccc}
\hline $\begin{array}{l}\text { Physical } \\
\text { quantity }\end{array}$ & Dimension & $\begin{array}{c}\text { Similarity } \\
\text { relation }\end{array}$ & Similarity ratio \\
\hline Length & $L$ & $l_{r}$ & $1: 25$ \\
Elastic modulus & $F L^{-2}$ & $E_{r}$ & $1: 32.5$ \\
Density & $F T L^{-4}$ & $\rho_{r}$ & $1: 1.3$ \\
Stress & $F L^{-2}$ & $\sigma_{r}=E_{r}$ & $1: 32.5$ \\
Acceleration & $L T^{-2}$ & $a_{r}=E_{r} \rho_{r}^{-1} l_{r}^{-1}$ & $1: 1$ \\
Poisson's ratio & - & $\mu_{r}=1$ & $1: 1$ \\
Friction angle & - & $\theta_{r}=1$ & $1: 1$ \\
\hline
\end{tabular}

Mohr-Coulomb yield criterion is $1.6 \%$ larger than that of the shaking table test, while that of the classical Mohr-Coulomb yield criterion is $5.5 \%$ smaller.

Figure 20 shows that the average peak acceleration error of the modified Mohr-Coulomb model is $+2.71 \%$ and the maximum relative error is $+8.91 \%$. The average error of the classical Mohr-Coulomb model is $-6.98 \%$, and the maximum relative error is $-8.87 \%$. The modified model has a lower average error than the classical model, and both models have similar maximum relative errors. In aseismic tunnel analysis, a larger acceleration peak value leads to a more conservative aseismic design.

\subsection{Displacement Analysis of the Modified Mohr-Coulomb} Model. The peak horizontal displacements are introduced as the measurements [30-32]. Displacement can be obtained by acceleration double integral for time. By comparing the displacement watch points of the two Mohr-Coulomb models with the results of the shaking table test, the maximum horizontal displacement similarity advantage of the modified Mohr-Coulomb yield criterion was assessed.

As shown in Figures 21-24, the displacements of the shaking table test and classical and modified Mohr-Coulomb yield criteria are in minus, which indicate that the models were moving towards the negative direction of the sensors. To simplify the following analysis, all displacements are taken as absolute values.

As reported in Table 9, the modified Mohr-Coulomb yield criterion has more similar maximum displacements 
TABle 3: Physical parameters of the surrounding rock.

\begin{tabular}{lccccc}
\hline & Density $\left(\mathrm{kg} / \mathrm{m}^{3}\right)$ & Elastic modulus $(\mathrm{MPa})$ & Poisson's ratio & Cohesion $(\mathrm{kPa})$ & Friction angle $\left(^{\circ}\right)$ \\
\hline Model material & 1300 & 1.07 & 0.25 & 3.06 & 25 \\
Prototype material & 1690 & 34.8 & 0.25 & 99.5 & 25 \\
Similarity ratio & $1: 1.3$ & $1: 32.5$ & $1: 1$ & $1: 32.5$ & $1: 1$ \\
\hline
\end{tabular}

TABle 4: Physical parameters of the linings.

\begin{tabular}{lccccc}
\hline & Density $\left(\mathrm{kg} / \mathrm{m}^{3}\right)$ & Elastic modulus $(\mathrm{MPa})$ & Poisson's ratio & Cohesion $(\mathrm{kPa})$ & Friction angle $\left({ }^{\circ}\right)$ \\
\hline Model material & 1780 & 571.42 & 0.2 & 60.71 & 50.8 \\
Prototype material & 2314 & 18571 & 0.2 & 1973 & 50.8 \\
Similarity ratio & $1: 1.3$ & $1: 32.5$ & $1: 1$ & $1: 32.5$ & $1: 1$ \\
\hline
\end{tabular}

TABle 5: Physical parameters of the faults.

\begin{tabular}{lccccc}
\hline & Density $\left(\mathrm{kg} / \mathrm{m}^{3}\right)$ & Elastic modulus $(\mathrm{MPa})$ & Poisson's ratio & Cohesion $(\mathrm{kPa})$ & Friction angle $\left({ }^{\circ}\right)$ \\
\hline Model material & 1500 & 0.71 & 0.25 & - & 35 \\
Prototype material & 1950 & 23 & 0.25 & - & 35 \\
Similarity ratio & $1: 1.3$ & $1: 32.5$ & $1: 1$ & - & $1: 1$ \\
\hline
\end{tabular}

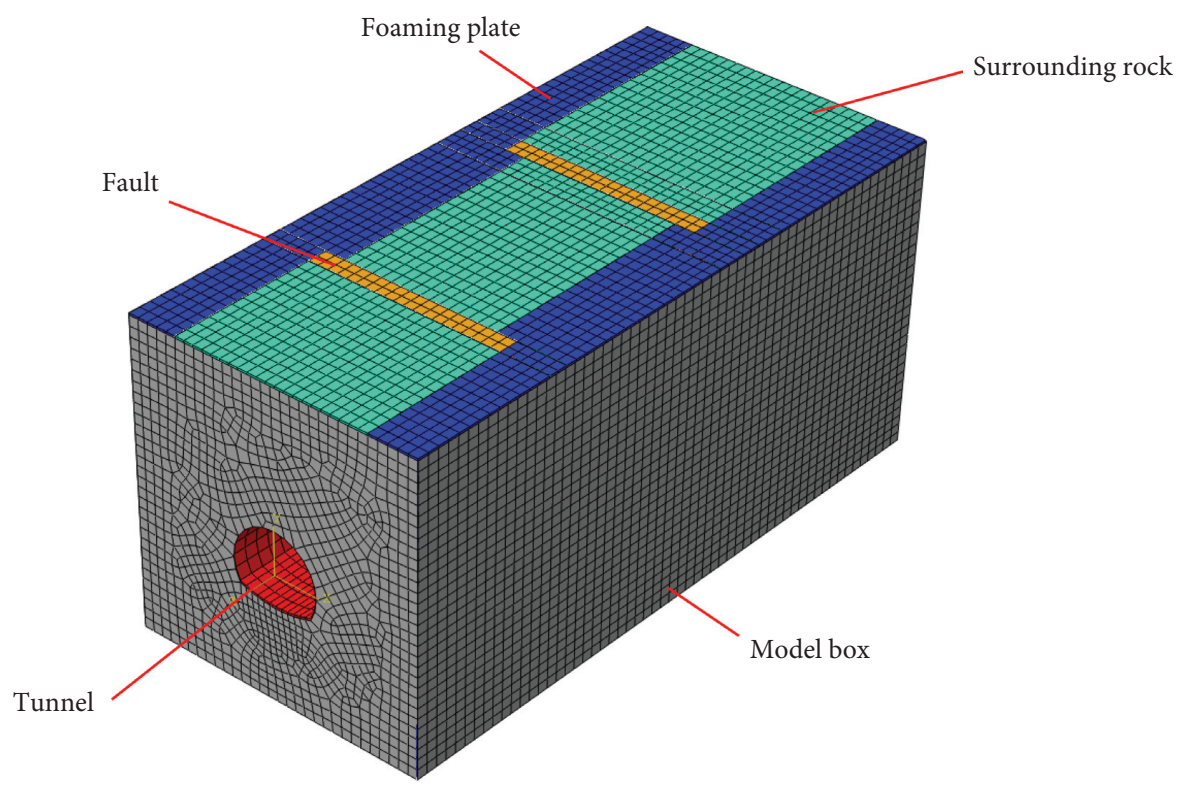

Figure 10: Computational model of the shaking table test.

TABle 6: Physical parameters of the materials.

\begin{tabular}{lccccc}
\hline & Density $\left(\mathrm{kg} / \mathrm{m}^{3}\right)$ & Elastic modulus $(\mathrm{MPa})$ & Poisson's ratio & Cohesion $(\mathrm{kPa})$ & Friction angle $\left(^{\circ}\right)$ \\
\hline Surrounding rock & 1300 & 1.07 & 0.25 & 3.06 & 25 \\
Linings & 1780 & 571.42 & 0.2 & 60.71 & - \\
Fault & 1500 & 0.71 & 0.25 & - & 30.8 \\
Q235 steel & 7500 & 210000 & 0.25 & - & - \\
Damping layer & 150 & 70 & 0.05 & - \\
\hline
\end{tabular}

than the classical Mohr-Coulomb yield criterion. Compared to the shaking table test, the displacement of the modified Mohr-Coulomb yield criterion at $\mathrm{A} 4 \mathrm{H}$ is $6.41 \%$ smaller, while that of the classical Mohr-Coulomb yield criterion is $10.68 \%$ smaller. At A5H, the displacement of the modified Mohr-Coulomb yield criterion is $5.37 \%$ larger than that of the shaking table test, while that of the classical Mohr-Coulomb yield criterion is $12.68 \%$ smaller.

Figure 25 shows that the average displacement error of the modified Mohr-Coulomb model is $+3.79 \%$ and the maximum relative error is $-6.41 \%$. The average displacement error of the classical Mohr-Coulomb model is $-8.47 \%$, and 


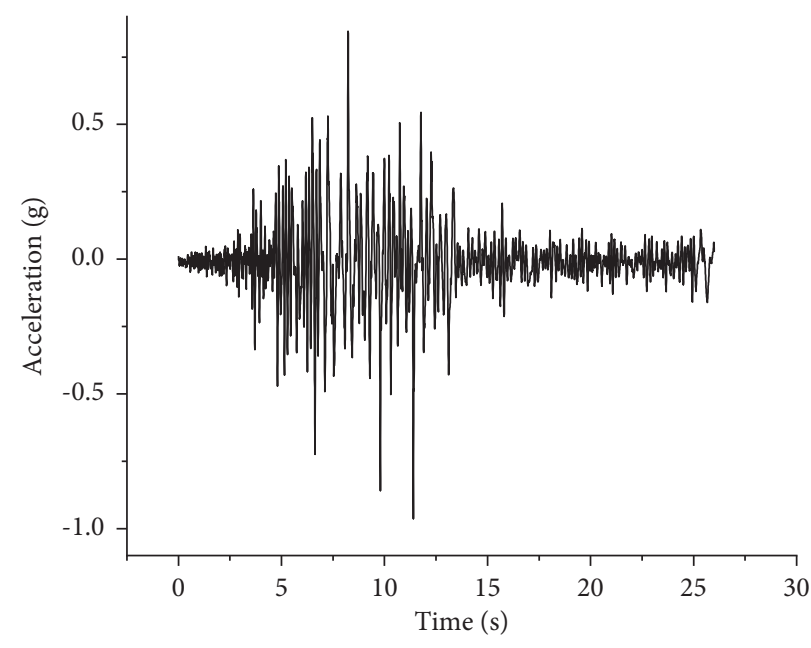

- Acceleration

FIgURE 11: Time history of the input wave of the numerical simulation.

TABLE 7: First six orders of the natural vibration frequency of the rock material.

\begin{tabular}{lcccccc}
\hline & 1st order & 2nd order & 3rd order & 4th order & 5th order & 6th order \\
\hline Natural vibratory circular frequencies $(\mathrm{rad} / \mathrm{s})$ & 8.98 & 12.58 & 18.705 & 19.304 & 23.185 & 23.58 \\
\hline
\end{tabular}

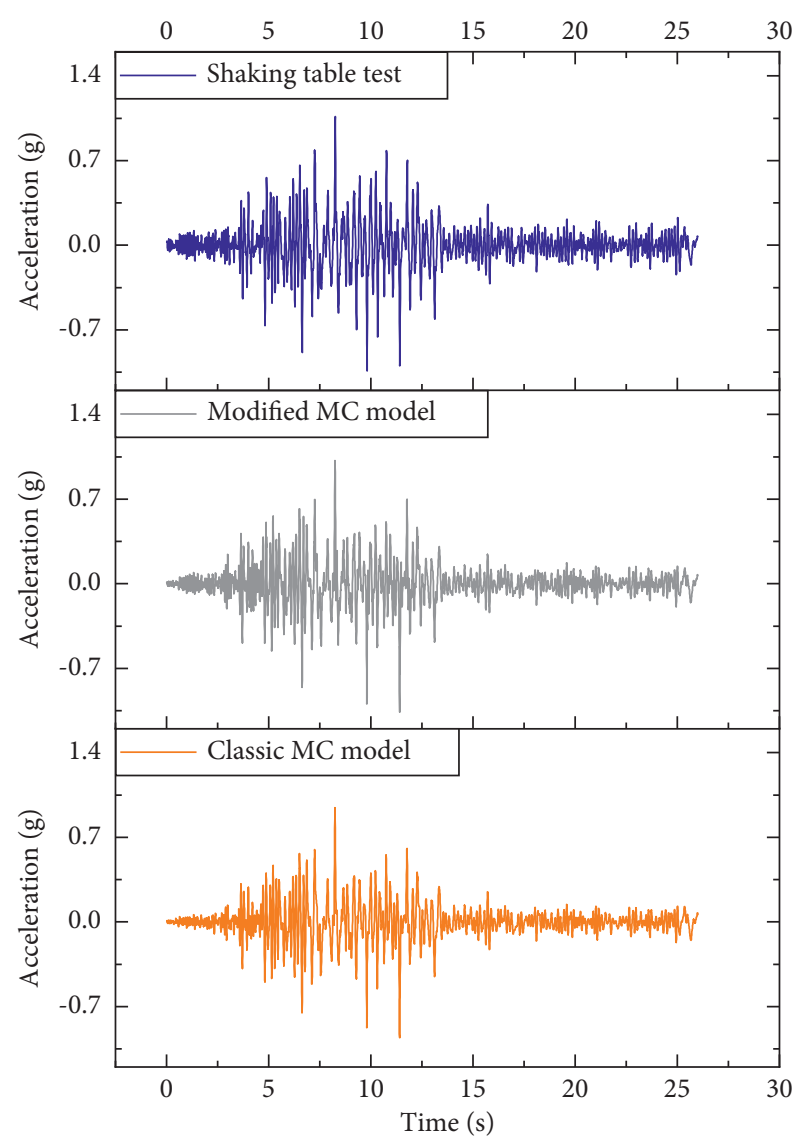

FIgURE 12: Acceleration time history at point A4H.

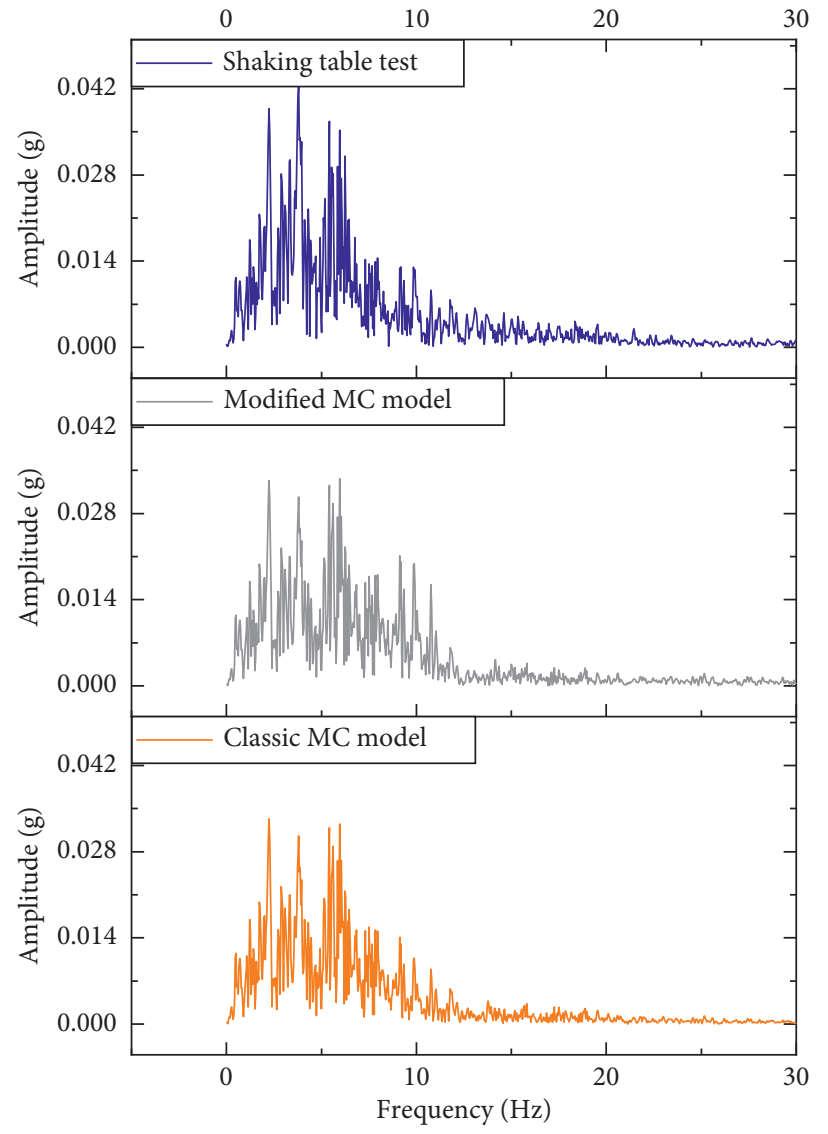

FIGURE 13: : Frequency-domain analysis of point A4H. 


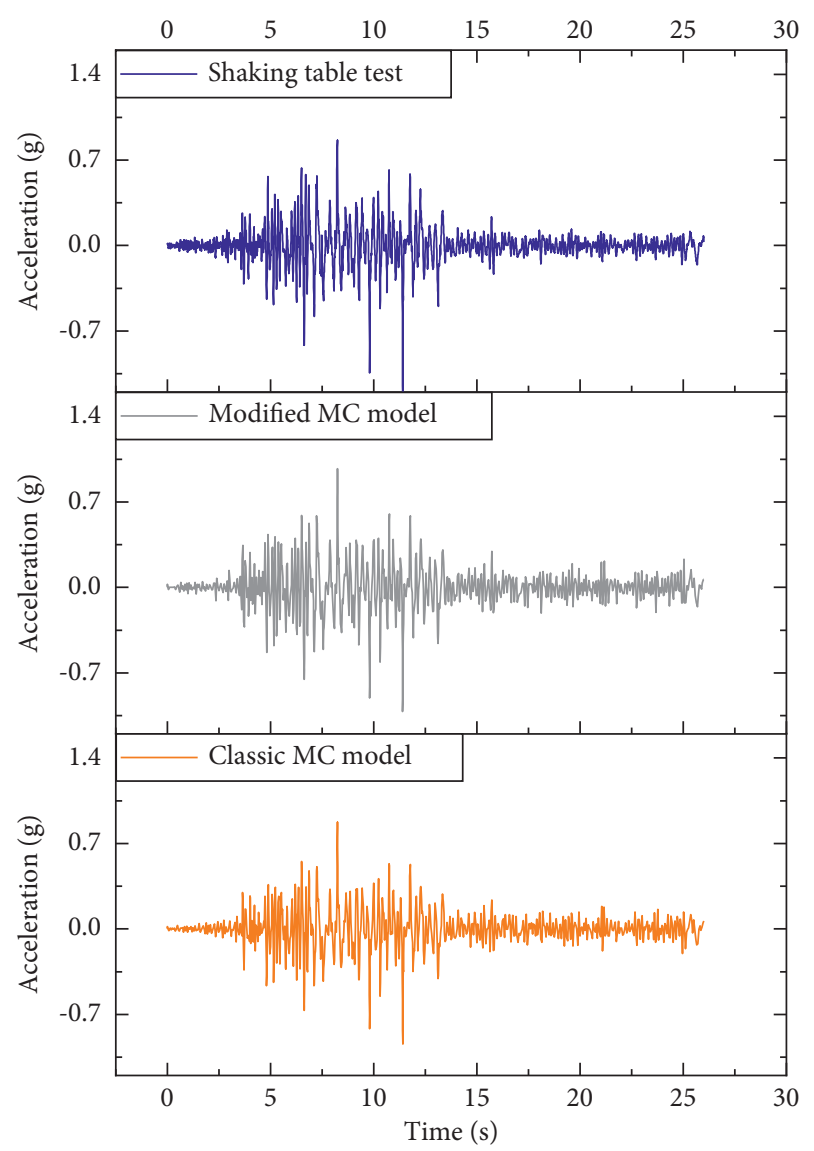

Figure 14: Acceleration time history at point A5H.

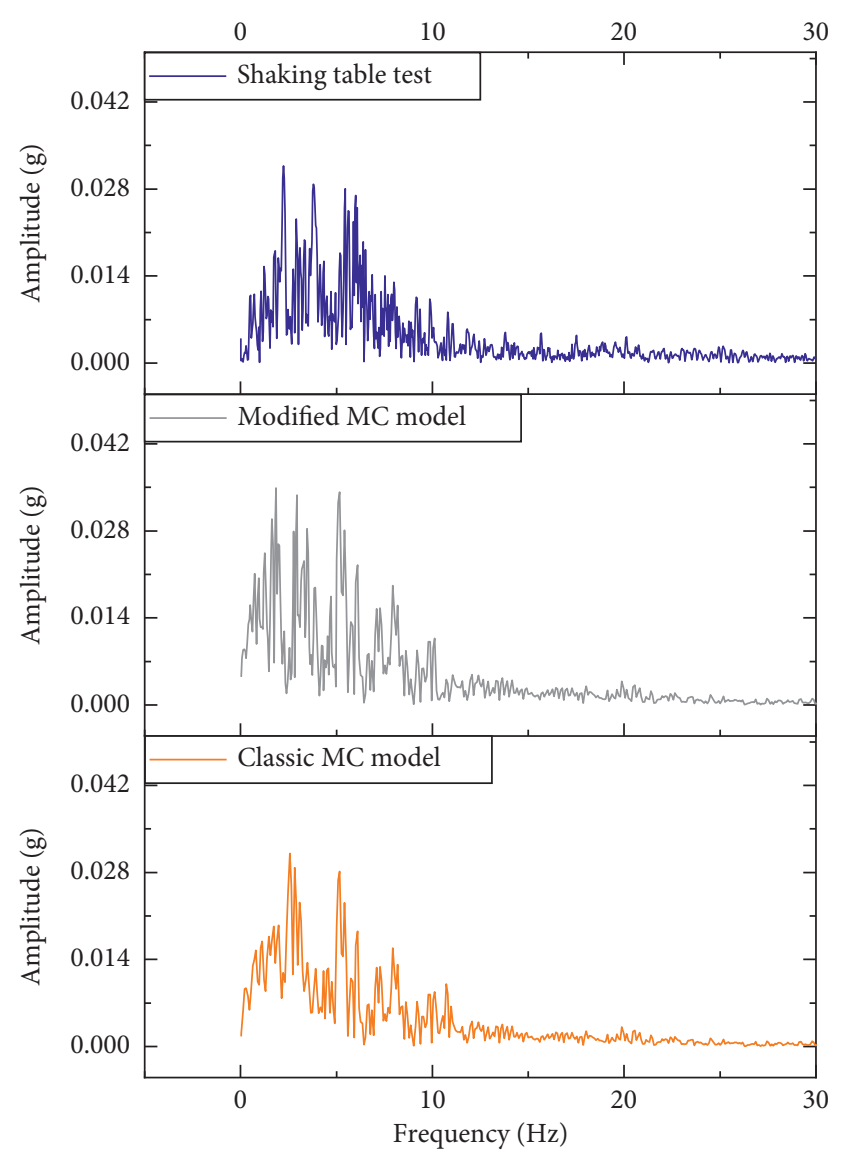

FIgURE 15: Frequency-domain analysis of point A5H.

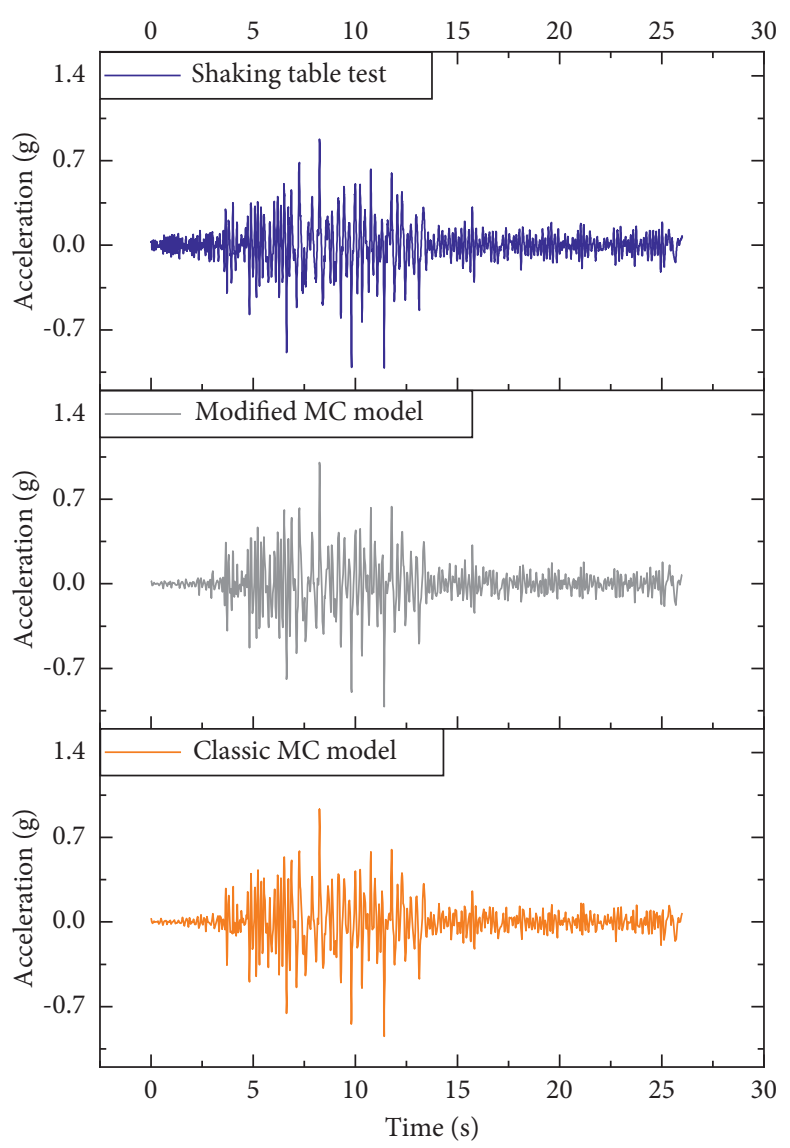

FIgURE 16: Acceleration time history at point $\mathrm{A} 6 \mathrm{H}$.

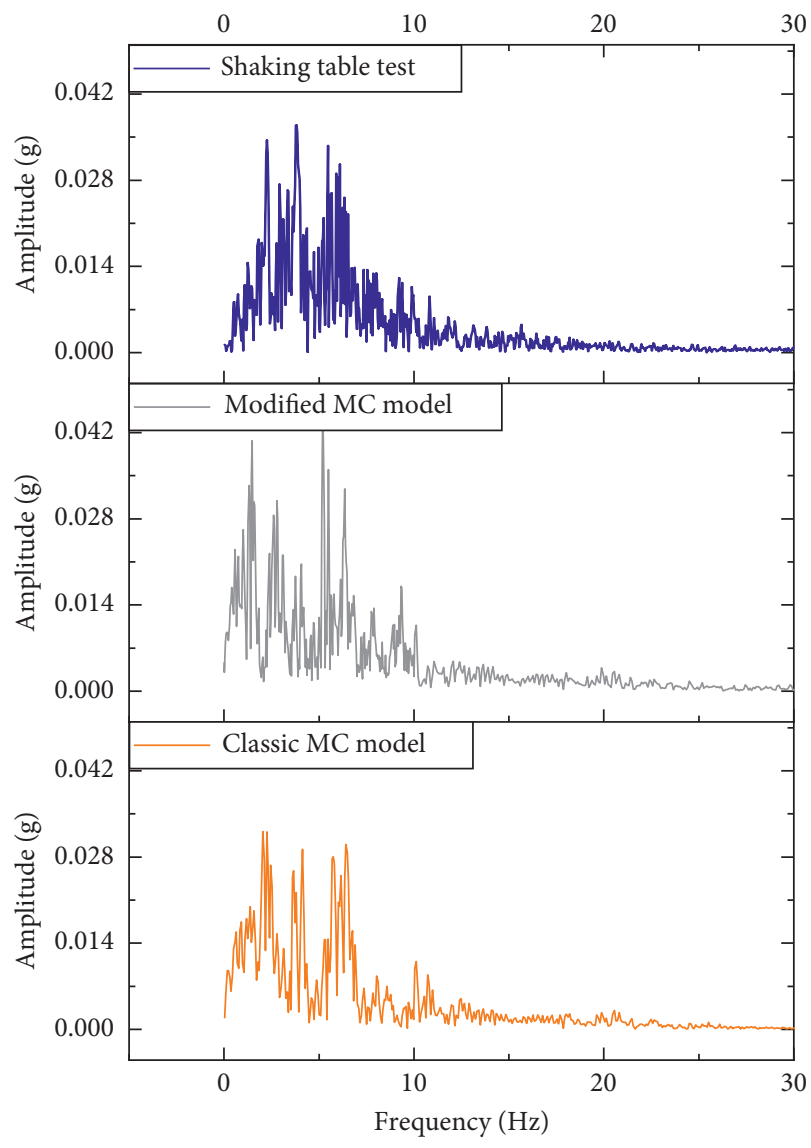

Figure 17: Frequency-domain analysis of point $\mathrm{A} 6 \mathrm{H}$. 


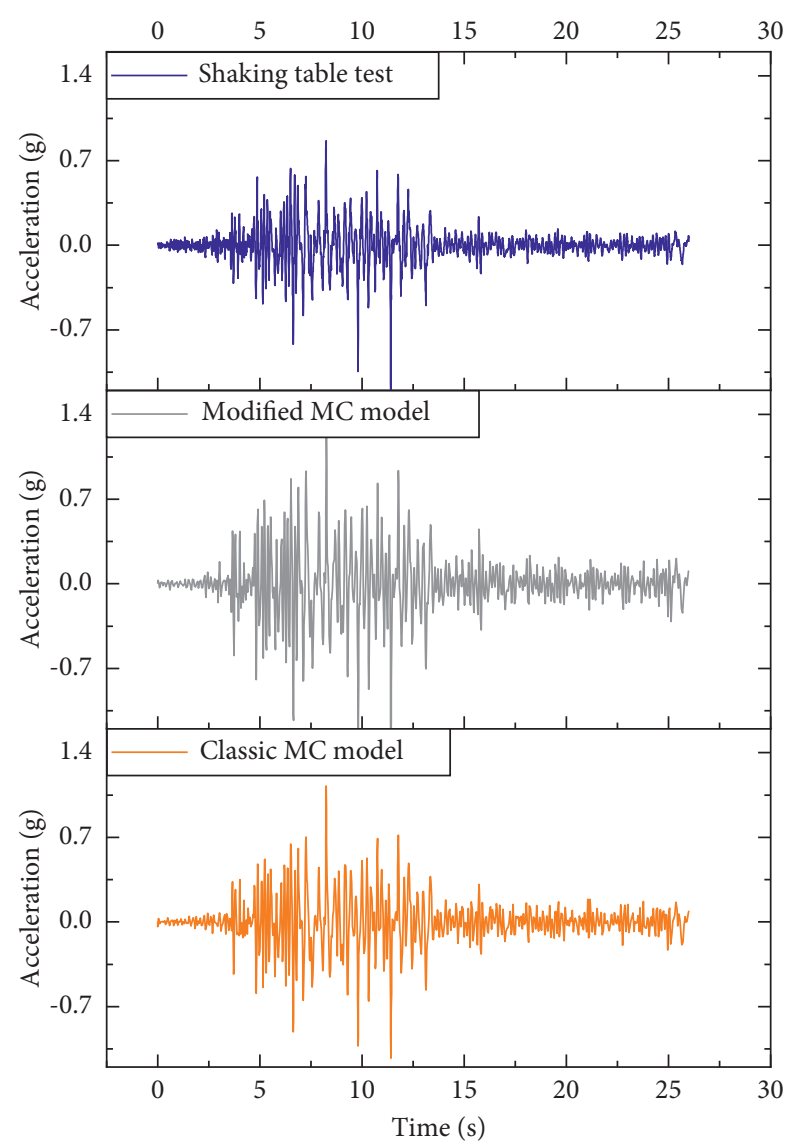

FIgURE 18: Acceleration time history at point A7H.

the maximum relative error is $-12.68 \%$. The modified model has both lower average and relative errors than the classical model.

4.5. Axial Force Analysis of the Modified Mohr-Coulomb Model. The peak axial forces are introduced as the measurements [33]. Axial forces can be obtained by calculating the stress or strain at monitoring points. In numerical simulations, axial forces can be obtained from the elemental solutions. The axial forces of the shaking table test could be calculated from

$$
N=\frac{1}{12} \operatorname{Ebh}\left(\varepsilon_{1}+\varepsilon_{2}\right)
$$

where $E$ is the elastic modulus of the lining, $b$ is the width of the element, $h$ is the thickness of the lining, and $\varepsilon_{1}$ and $\varepsilon_{2}$ are the strains of inner and outer surfaces at the watch point.

In this article, $E=571.42 \mathrm{MPa}, b=0.064 \mathrm{~m}$, and $h=0.01 \mathrm{~m}$.

As shown in Figures 26 and 27, there are both positive and negative numbers of the axial forces of the shaking table test and classical and modified Mohr-Coulomb yield criteria, which indicate that the models were tensioned (positive numbers) and compressed (negative numbers). To simplify the following analysis, all axial forces are taken as absolute values.

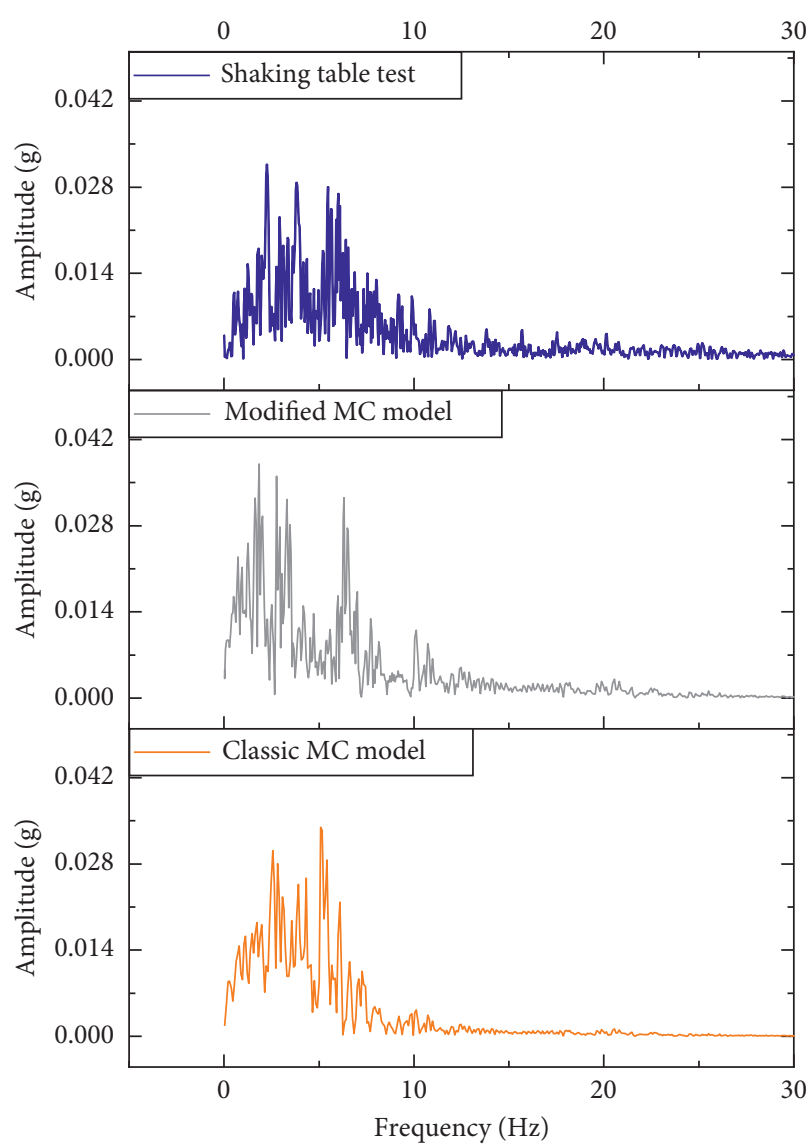

Figure 19: Frequency-domain analysis of point A7H.

TABLE 8: Maximum accelerations at the monitoring points for the different yield criterion models (unit: g).

\begin{tabular}{cccc}
\hline Point & Shaking table test & Classical MC model & $\begin{array}{c}\text { Modified MC } \\
\text { model }\end{array}$ \\
\hline A4H & 1.037 & 0.945 & 1.017 \\
A5H & 0.980 & 0.944 & 1.016 \\
A6H & 1.014 & 0.945 & 1.016 \\
A7H & 1.234 & 1.128 & 1.344 \\
\hline
\end{tabular}

In Table 10, the modified Mohr-Coulomb yield criterion has more similar maximum axial forces than the classical Mohr-Coulomb yield criterion. Compared to the shaking table test, the maximum axial force of the modified Mohr-Coulomb yield criterion at the crown of section 1 is $6.03 \%$ higher, while that of the classical Mohr-Coulomb yield criterion is $16.96 \%$ smaller. At the invert of section 2 , the maximum axial force of the modified Mohr-Coulomb yield criterion is $3.10 \%$ larger than that of the shaking table test, while that of the classical Mohr-Coulomb yield criterion is $18.83 \%$ smaller.

Figures 28 and 29 show that the average axial forces error of the modified Mohr-Coulomb model is $+7.56 \%$ and the maximum relative error is $+17.55 \%$. The average axial force error of the classical Mohr-Coulomb model is $-23.93 \%$, and the maximum relative error is $-27.0 \%$. The modified model has both lower average and relative errors than the classical 
(\%)

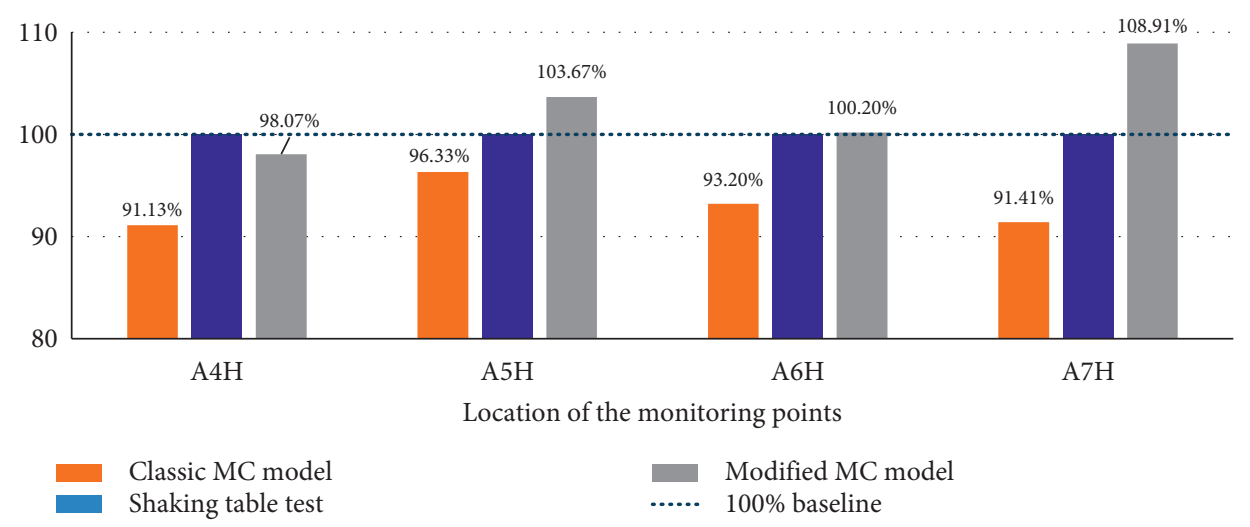

Figure 20: Histogram of the maximum accelerations at all monitoring points for the different yield criterion models.

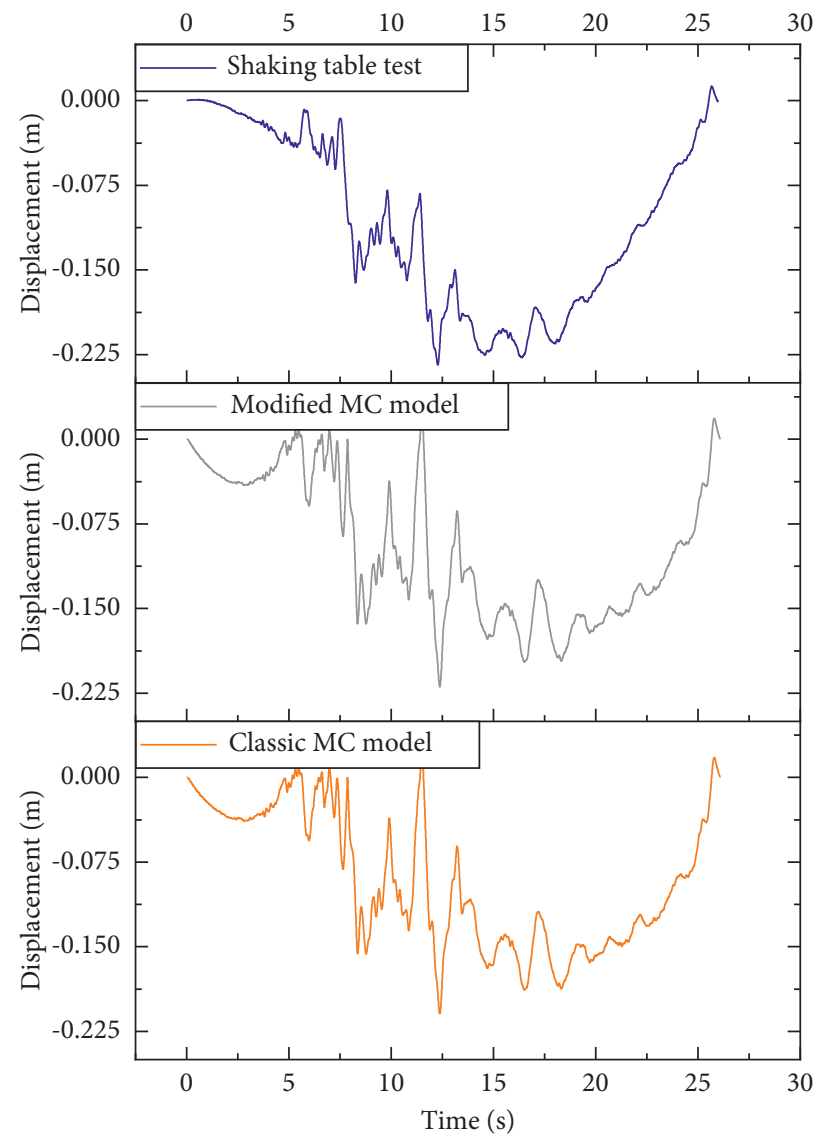

FIGURE 21: Displacement time history at point A4H. 


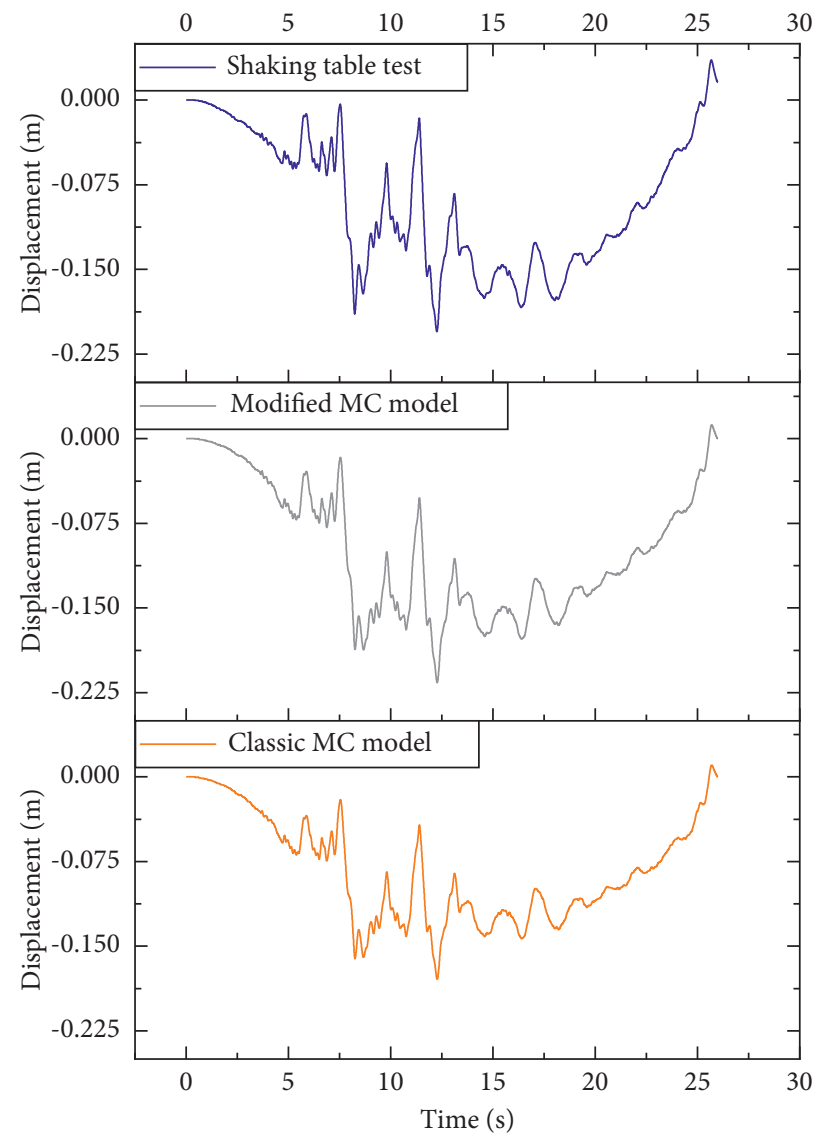

Figure 22: Displacement time history at point A5H.

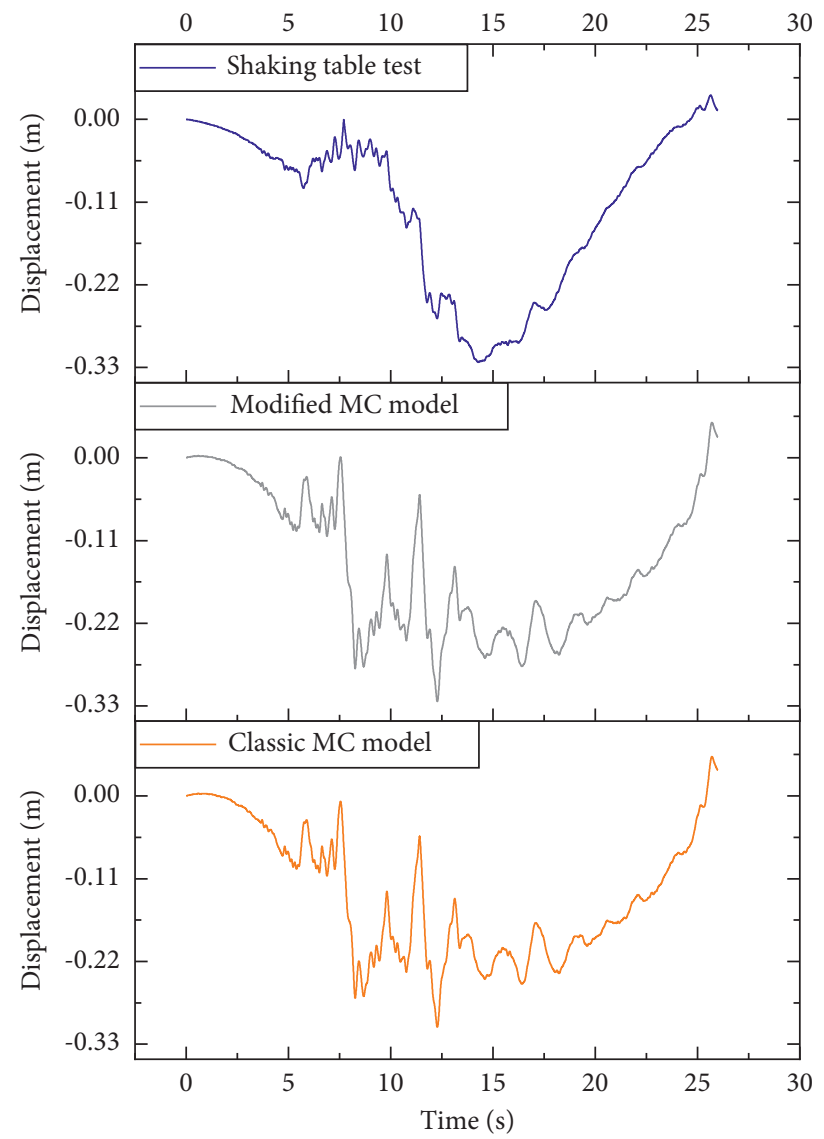

Figure 23: Displacement time history at point A6H. 


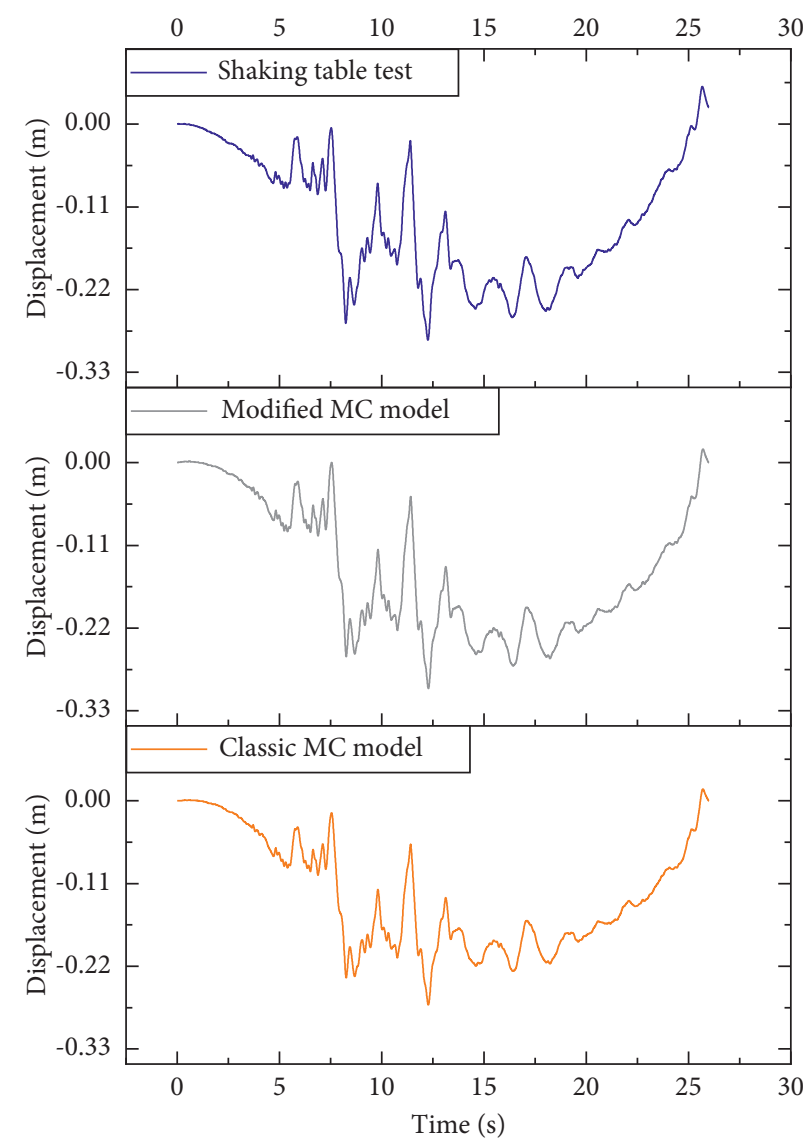

Figure 24: Displacement time history at point A7H.

TABle 9: Maximum displacements at the monitoring points for the different yield criterion models (unit: $\mathrm{m}$ ).

\begin{tabular}{lccc}
\hline Point & Shaking table test & Classical MC model & Modified MC model \\
\hline A4H & 0.234 & 0.209 & 0.219 \\
A5H & 0.205 & 0.179 & 0.216 \\
A6H & 0.323 & 0.307 & 0.324 \\
A7H & 0.287 & 0.271 & 0.300 \\
\hline
\end{tabular}

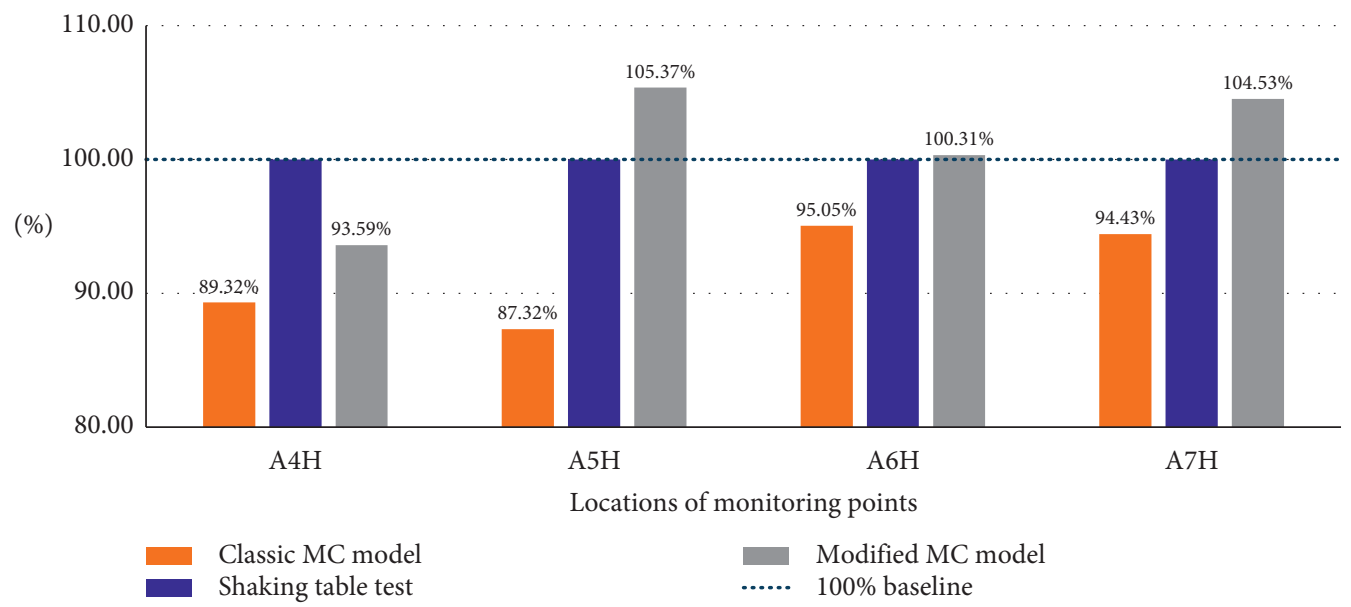

FIGURE 25: Histogram of the maximum displacements at all monitoring points for the different yield criterion models. 


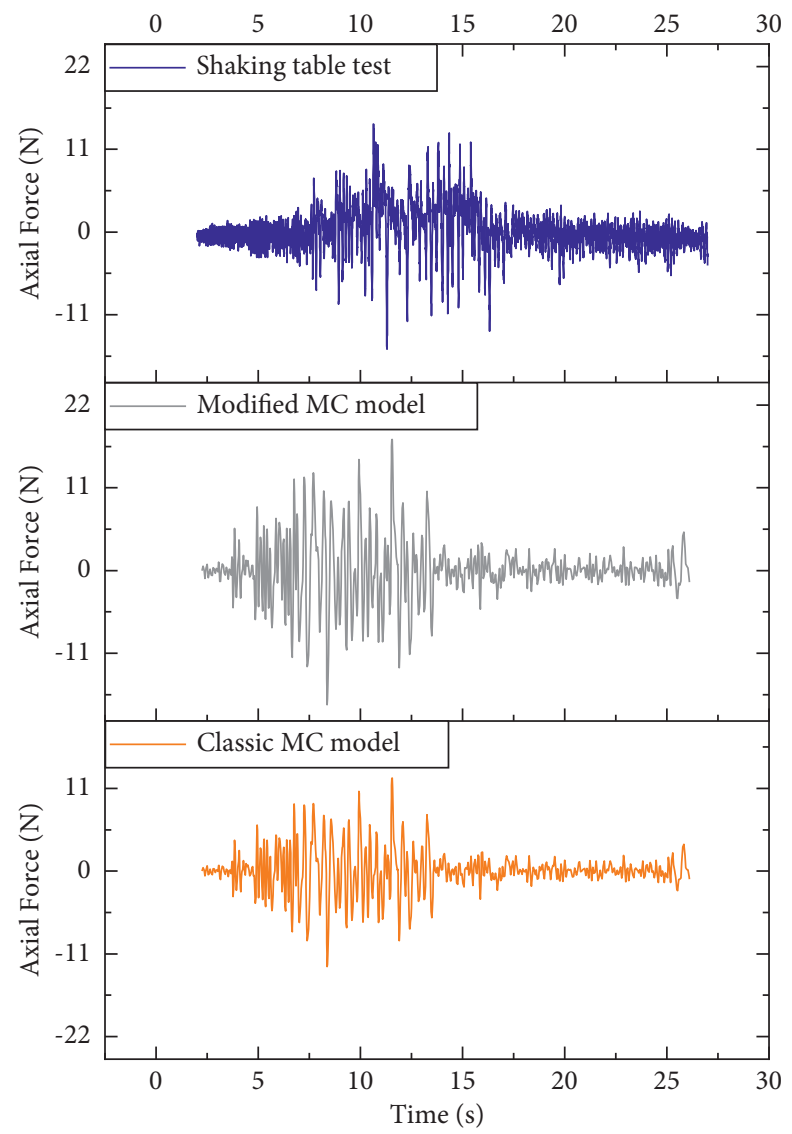

FIgURE 26: Axial force time history of section 1 spandrel.

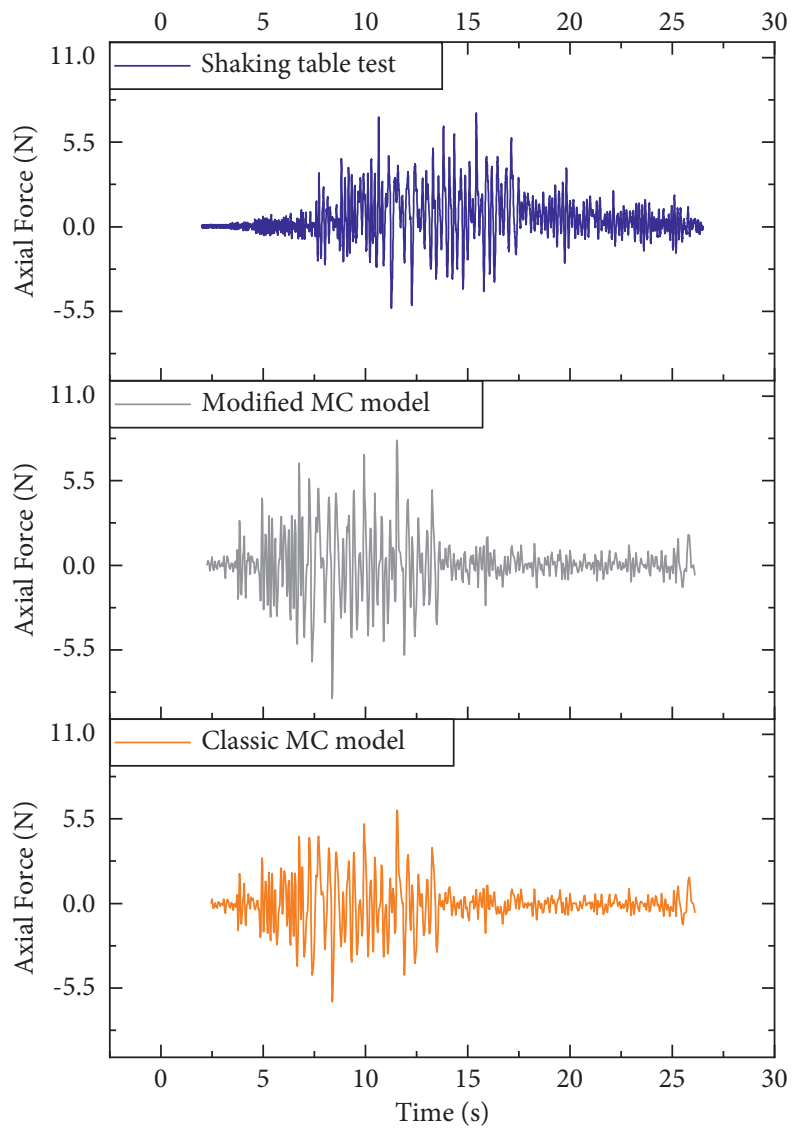

Figure 27: : Axial force time history of section 2 arch springing. 
TABLE 10: Maximum axial forces at the monitoring points for the different yield criterion models (unit: N).

\begin{tabular}{lcccc}
\hline Section & Point & Shaking table test & Classical MC model & Modified MC model \\
\hline 1 & Crown & 7.96 & 6.61 & 8.44 \\
1 & Spandrel & 15.61 & 11.35 & 17.82 \\
1 & Sidewall & 8.31 & 6.13 & 8.62 \\
1 & Arch springing & 28.13 & 19.69 & 30.66 \\
1 & Invert & 9.72 & 4.48 & 10.50 \\
2 & Crown & 5.76 & 4.32 & 5.88 \\
2 & Spandrel & 6.60 & 3.82 & 6.73 \\
2 & Sidewall & 4.10 & 6.39 & 4.51 \\
2 & Arch springing & 7.35 & 1.06 & 8.64 \\
2 & Invert & 1.29 & & 1.33 \\
\hline
\end{tabular}

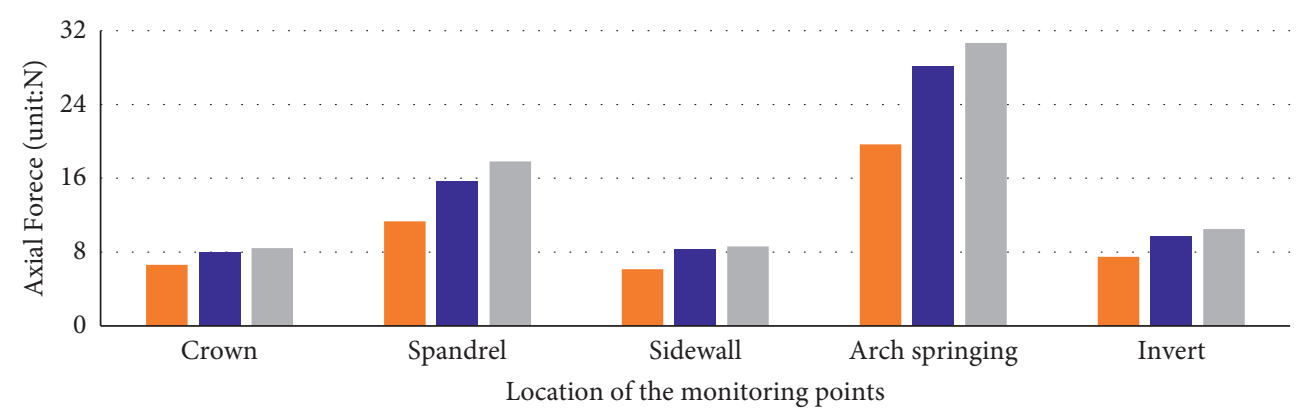

- Classic MC model

- Shaking table test

- Modified MC model

FIGURE 28: Histogram of the maximum axial forces at section 1 for the different yield criterion models.

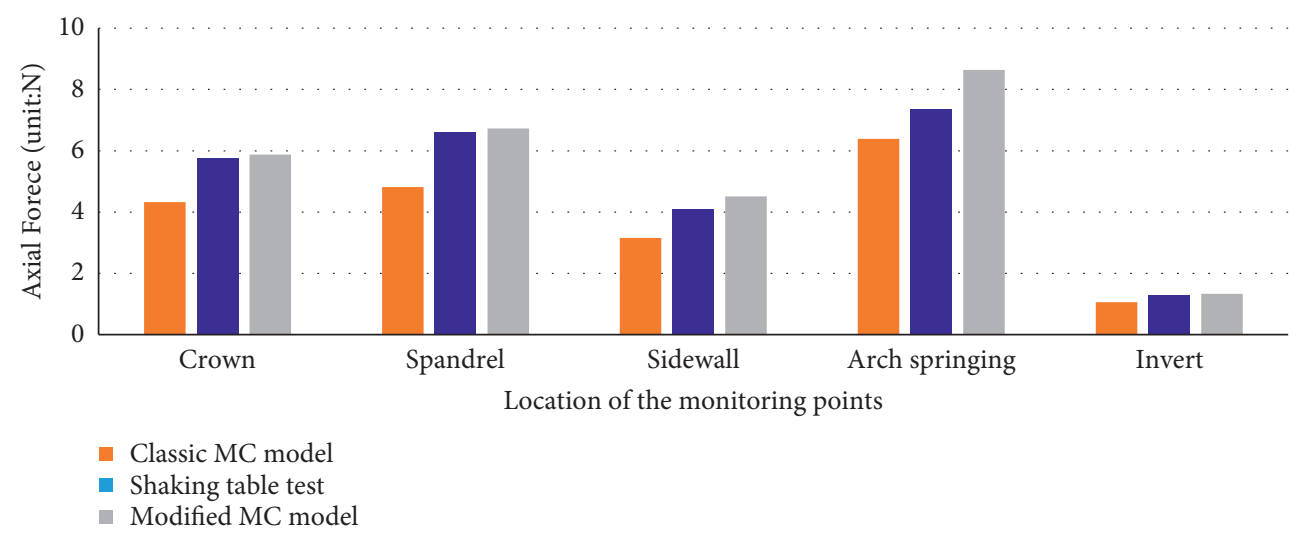

FIGURE 29: Histogram of the maximum axial forces at section 2 for the different yield criterion models.

model. In conclusion, the modified Mohr-Coulomb model exhibits a better performance in simulating the dynamic response of rocks during high-intensity horizontal earthquake.

\section{Conclusions}

The modified Mohr-Coulomb model was successfully developed and used to analyse the dynamic response of tunnels during high-intensity earthquakes:

(1) Compared to the shaking table test, the classical Mohr-Coulomb model has a relatively large average error $(-6.98 \%$ in peak accelerations, $-8.47 \%$ in maximum displacements, and $-23.93 \%$ in axial forces), while the modified Mohr-Coulomb model has a smaller average error $(+2.71 \%$ in peak accelerations, $+3.79 \%$ in maximum displacements, and $+7.56 \%$ in axial forces).

(2) The absolute values of the maximum acceleration relative errors of the two models are similar. Compared to the shaking table test, the classical Mohr-Coulomb model has a $+8.91 \%$ maximum relative error and the modified Mohr-Coulomb model has a $-8.87 \%$ maximum relative error. The 
classical Mohr-Coulomb model has larger relative errors in displacements $(-12.68 \%)$ and axial forces $(-27.0 \%)$ than those of the modified Mohr-Coulomb model $(-6.41 \%$ in displacements and $+17.55 \%$ in axial forces).

(3) The new modified model has better waveforms in the low frequency band $(0-10 \mathrm{~Hz})$ than the classical Mohr-Coulomb model. In the higher frequency band $(>15 \mathrm{~Hz})$, the difference between the two models is negligible.

(4) The classical Mohr-Coulomb model overshoots the tensile properties of the geotechnical materials, which leads to higher yield stresses in simulating the surrounding rocks of the shaking table test. The greater the dynamic stress the rock bears, the less the dynamic stress the tunnel lining bears during the earthquake. Less dynamic stress of the lining leads to lower peak accelerations, lower maximum displacements, and fewer axial forces, which match the numerical simulation results. The modified Mohr-Coulomb model reduces the yield stresses of surrounding rocks and brings the simulation results closer to the shaking table test data.

The new modified Mohr-Coulomb yield criterion has overall closer results in simulating the accelerations, displacements, and axial forces of the tunnel linings in the horizontal shaking table test than the classical Mohr-Coulomb yield criterion. Since most seismic wave energy is in the low frequency band (Figure 9), the modified Mohr-Coulomb yield criterion works better than the classical one. Moreover, the modified criterion presented in this article improves Jia's equation by replacing the undefined parameter $m$ with the tensile strength.

\section{Data Availability}

The data used to support the findings of this study are included within the article. The data are also available from the corresponding author upon request.

\section{Conflicts of Interest}

The authors declare that there are no conflicts of interest regarding the publication of this paper.

\section{Acknowledgments}

The authors thank LetPub (https://www.letpub.com) for its linguistic assistance and scientific consultation during the preparation of this manuscript. This study was funded by the National Natural Science Foundation of China (Nos. 51778540, 5167850, and 52108361). This research was also supported by the Miaozi Engineering Key Project from Science and Technology Department of Sichuan Province (No. 2020JDRC0078) and the State Key Laboratory of Geohazard Prevention and Geoenvironment Protection (China) Open Fund (No. SKLGP2020K018).

\section{References}

[1] P. Geng, "Research on the seismic calculation method of railway tunnel," $\mathrm{Ph}$. D. thesis, Southwest Jiaotong University, 2011.

[2] W. Zhang, "Current construction and earthquake-resistant design for tunnels in Japan," World Earthquake Engneering, no. 2, pp. 68-71, 2006.

[3] Q. H. Qian and C. He, Dynamic Response of Tunnels and the Analysis of Tunnel Damage and its Revelation from Wenchuan Earthquake, 2009.

[4] H. Zhou, X. H. Wang, C. D. He, and C. X. Huang, "Seismic response of a tunnel embedded in compacted clay through large-scale shake table testing," Shock and Vibration, vol. 2018, Article ID 5968431, 17 pages, 2018.

[5] D. Y. Wang, J. X. Yan, G. Y. Cui, J. Liu, and H. Wang, "Experimental study on characteristics of seismic damage and damping Technology of absorbing joint of tunnel crossing interface of soft and hard rock," Shock and Vibration, vol. 2020, Article ID 2128045, 13 pages, 2020.

[6] Z. Y. Ouyang, J. Cui, R. F. Luo, and P. J. Li, "Shaking table test of seismic response of immersed tunnels under the influence of multiple factors," Shock and Vibration, vol. 2020, Article ID 8858486, 17 pages, 2020.

[7] H. Lei, H. G. Wu, and T. W. Lai, "Shaking table tests for seismic response of oblique overlapped tunnel," Shock and Vibration, vol. 2021, Article ID 8816755, 19 pages, 2021.

[8] Y. Shen, B. Gao, and Y. Wang, "Structural dynamic properties analysis for portal part of mountain tunnel in strong earthquake area," Chinese Journal of Rock Mechanics and Engineering, vol. 28, no. 1, 2009.

[9] M. Kiani, T. Akhlaghi, and A. Ghalandarzadeh, "Experimental modeling of segmental shallow tunnels in alluvial affected by normal faults," Tunnelling and Underground Space Technology, vol. 51, pp. 108-119, 2016.

[10] L. I. Lin, C. He, P. Geng, and D. Cao, "Study of shaking table model test for seismic response of portal section of shallow un-symmetrical loading tunnel," Chinese Journal of Rock Mechanics and Engineering, vol. 30, no. 12, 2011.

[11] C. Xin, B. Gao, and J. Zhou, "Shaking table tests on performances of anti-seismic and damping measures for fault crossing tunnel structures," Chinese Journal of Geotechnical Engineering, vol. 36, no. 8, 2014.

[12] D. Y. Wang, S. Q. Jia, G. Y. Cui, Y. Yang, and J. Chang, "Model test on bearing characteristics of basalt fiber-reinforced concrete lining," Advances in Materials Science and Engineering, vol. 2020, Article ID 3891343, 10 pages, 2020.

[13] P. Geng, Y. He, C. He, D. Cao, Q. L. Quan, and Q. X. Yang, "Study of shaking table model test for seismic response of portal section of shallow unsymmetrical loading tunnel," Chinese Journal of Rock Mechanics and Engineering, vol. 33, no. 2, pp. 358-365, 2014.

[14] S. P. Jia, "Hydro-mechanical coupled creep damage constitutive model of Boom clay, back analysis of model parameters and its engineering application," Ph. D. Thesis, Wuhan Institute of Rock \& Soil Mechanics, Chinese Academy of Sciences , 2009.

[15] C. J. Deng, G. J. He, and Y. R. Zheng, "Studies on DruckerPrager yield criterions based on M-C yield criterion and application in geotechnical engineering," Chinese Journal of Geotechnical Engineering, no. 6, pp. 735-739, 2006.

[16] Z. H. Dai and P. S. Shen, "Simplified form and applications of Mohr-Coulomb equivalent area circle yield criterion," Journal 
of Fuzhou University (Natural Science), no. 4, pp. 454-459, 2003.

[17] G. C. Xu and Y. R. Zheng, "Study on Application of yield criterion in rock engineering," Journal of geotechnical engineering, no. 2, pp. 93-99, 1990.

[18] J. L. Liu and Y. Xia, "Discussion on Studies on Drucker-Prager yield criterions based on $\mathrm{M}-\mathrm{C}$ yield criterion and application in geotechnical engineering," Chinese Journal of Geotechnical Engineering, no. 12, pp. 2168-2169, 2006.

[19] O. C. Zienkiewicz and G. N. Pande, "Some useful forms of isotropic yield surfaces for soil and rock mechanics," in Finite Elements in Geomechanics, G. Godehus, Ed., pp. 179-190, Wiley, New York, NY, USA, 1977.

[20] S. P. Jia, W. Z. Chen, J. P. Yang, and P. S. Chen, "An elastoplastic constitutive model based on modified Mohr-Coulomb criterion and its numerical implementation," Rock and Soil Mechanics, vol. 31, no. 7, pp. 2051-2058, 2010.

[21] C. L. Xin, Z. Z. Wang, and B. Gao, "Shaking table tests on seismic response and damage mode of tunnel linings in diverse tunnel-void interaction states," Tunnelling and Underground Space Technology, vol. 77, pp. 295-304, 2018.

[22] C. L. Xin, Z. Z. Wang, and J. Yu, "The evaluation on shock absorption performance of buffer layer around the cross section of tunnel lining," Soil Dynamics and Earthquake Engineering, vol. 131, p. 13, Article ID 106032, 2020.

[23] Sac, Code for Design on Tunnel of Railway, Ministry of Railways of the People's Republic of China, Beijing, China, 2005.

[24] S. Z. Shi and G. H. Yang, "An improvement of the commonly used yield function for rock material," Chinese Journal of Geotechnical Engineering, vol. 1987, no. 4, pp. 60-69, 1987.

[25] C. L. Xin, Z. Z. Wang, J. M. Zhou, and B. Gao, "Shaking table tests on seismic behavior of polypropylene fiber reinforced concrete tunnel lining," Tunnelling and Underground Space Technology, vol. 88, pp. 1-15, 2019.

[26] Q. Zheng, C. L. Xin, Y. S. Shen, M. Huang, and B. Gao, "Seismic damage prediction method for lining structures based on the SEDR principle," Shock and Vibration, vol. 2021, Article ID 6637909, 13 pages, 2021.

[27] Y. S. Shen, Z. Z. Wang, J. Yu, X. Zhang, and B. Gao, "Shaking table test on flexible joints of mountain tunnels passing through normal fault," Tunnelling and Underground Space Technology, vol. 98, p. 12, Article ID 103299, 2020.

[28] Z. Z. Wang, L. Jiang, and Y. Gao, "Shaking table test of seismic response of immersed tunnels under effect of water," Soil Dynamics and Earthquake Engineering, vol. 116, no. 116, pp. 436-445, 2019.

[29] Z. Z. Wang, Y. J. Jiang, and C. A. Zhu, "Seismic energy response and damage evolution of tunnel lining structures," European Journal of Environmental and Civil Engineering, vol. 23, pp. 758-770, 2019.

[30] J.-B. Zhu, Y.-S. Li, S.-Y. Wu, R. Zhang, and L. Ren, "Decoupled explosion in an underground opening and dynamic responses of surrounding rock masses and structures and induced ground motions: a FEM-DEM numerical study," Tunnelling and Underground Space Technology, vol. 82, no. 82, pp. 442-454, 2018.

[31] X. F. Deng, S. G. Chen, J. B. Zhu, Y. X. Zhou, Z. Y. Zhao, and J. Zhao, "UDEC-AUTODYN hybrid modeling of a large-scale underground explosion test," Rock Mechanics and Rock Engineering, vol. 48, pp. 737-747, 2015.

[32] X. F. Deng, J. B. Zhu, S. G. Chen, Z. Y. Zhao, Y. X. Zhou, and J. Zhao, "Numerical study on tunnel damage subject to blast- induced shock wave in jointed rock masses," Tunnelling and Underground Space Technology, vol. 43, pp. 88-100, 2014.

[33] Y. Shen, B. Gao, X. Yang, and S. Taoau, "Seismic damage mechanism and dynamic deformation characteristic analysis of mountain tunnel after Wenchuan earthquake," Engineering Geology, vol. 180, pp. 85-98, 2014. 